\title{
Fast descent routes from within or near the stratosphere to the surface at Fukuoka, Japan, studied using ${ }^{7}$ Be measurements and trajectory calculations
}

\author{
Hisanori Itoh ${ }^{1}$ and Yukinori Narazaki ${ }^{2}$ \\ ${ }^{1}$ Department of Earth and Planetary Sciences, Kyushu University, 744, Motooka, Nishi, Fukuoka, 819-0395, Japan \\ ${ }^{2}$ Fukuoka Institute of Health and Environmental Sciences, 39, Mukai-Zano, Dazaifu, Fukuoka, 818-0315, Japan
}

Correspondence to: Hisanori Itoh (itoh@weather.geo.kyushu-u.ac.jp)

Received: 22 November 2015 - Published in Atmos. Chem. Phys. Discuss.: 8 December 2015

Revised: 29 April 2016 - Accepted: 7 May 2016 - Published: 24 May 2016

\begin{abstract}
By using high concentrations of ${ }^{7} \mathrm{Be}$ as an indicator, we clarify fast descent routes from within or near the stratosphere to Earth's surface, with the study site being in Fukuoka, Japan. Most routes arise from high latitudes through the following processes. First, the descent associated with a tropopause fold occurs, followed by southward movement with slow descent at the rear side of a strong trough. Because this motion occurs along an isentropic surface, the descending air parcels nearly conserve the potential temperature. As an extension, a strong descent associated with a sharp drop in the isentropic-surface height occurs at the southern edge of the trough; this transports air parcels to low altitudes. This process involves irreversible phenomena such as filamentation and cutoff of potential vorticity. Finally, upon meeting appropriate near-surface disturbances, parcels at low altitudes are transported to Earth's surface.

In some cases, parcels descend within midlatitudes. In such routes, because the potential temperature is much higher at high altitudes than at low altitudes, descent with conservation of the potential temperature is impossible, and the potential temperature decreases along the trajectories through mixing.

The prevalence of the high-latitude route is explained as follows. In the midlatitude route, because parcels at high and relatively low altitudes mix, the high concentrations of ${ }^{7} \mathrm{Be}$ included in high-altitude parcels are difficult to maintain. Therefore, for parcels to arrive at low altitudes in the midlatitude while maintaining high concentrations of ${ }^{7} \mathrm{Be}$, i.e., conserving the potential temperature, their area of origin
\end{abstract}

should be high altitudes in high latitudes where the potential temperature is almost the same as that in the arrival area.

In spring, tropopause folds are frequent in high latitudes, disturbances in the southward transport of parcels are strong, and disturbances occur by which parcels descend to the surface. Therefore, high concentrations of ${ }^{7} \mathrm{Be}$ occur most frequently in spring.

\section{Introduction}

Stratosphere-to-troposphere transport (STT) has attracted much research interest in the fields of atmospheric dynamics and chemistry and environmental science. Therefore, numerous studies have focused on STT since its investigations started in the 1950s (e.g., Reed and Sander, 1953; Machta, 1957). Thus far, the average features of the STT have been clarified considerably (e.g., Holton et al., 1995; Stohl et al., 2003; US Environmental Protection Agency, 2006). The intrusion of stratospheric air into the extratropical troposphere involves synoptic-scale and mesoscale processes, among which tropopause folds and cutoff lows are the most important (Stohl et al., 2003; Sprenger et al., 2003, Nieto et al., 2008). However, many STT studies have focused on stratospheric air infiltration to the troposphere and have therefore only examined the transport process to the upper and mid-troposphere.

Only recently have fully fledged studies on deep intrusions to the troposphere (deep STT) been conducted, even though, before the 2000s, there were several papers show- 
ing that stratospheric intrusions influence surface ozone (e.g., Oltmans and Levy II, 1992). By using 1-year reanalysis data from the European Centre for Medium-Range Weather Forecasts (ECMWF), Wernli and Bourqui (2002) obtained numerous forward trajectories to arrive below the $700 \mathrm{hPa}$ level within a 4-day period. As a result, it was confirmed that deep STT occurs frequently during winter and that its source regions are the storm tracks between 40 and $50^{\circ} \mathrm{N}$. Furthermore, the geographical distribution of deep STT events was shown to be different from that of full sets of STT events. By extending the analysis period to 15 years, Sprenger and Wernli (2003) conducted similar analyses, the results of which nearly matched those of Wernli and Bourqui (2002). They further examined destinations, in which the maximum was shown to be along the west coast of North America. James et al. (2003a, b), by using a Lagrangian particle dispersion model, extended the considered timescales and included transport processes such as convection and turbulence that were not included in the trajectory model. Škerlak et al. (2014) investigated deep STT by using 33-year ECMWF reanalysis data. According to their results, deep STT shows especially strong geographical and seasonal variations. The global hot spots for deep STT include the west coast of North America and the Tibetan Plateau, particularly in boreal winter and spring. However, in these studies, the descent mechanism was not examined.

Because the deepest area of the troposphere is just above the Earth's surface, a study of descending air from the stratosphere to the surface is very intriguing as "the deepest STT". Furthermore, if rapidly descending air from the stratosphere exists on the surface, it is interesting to note how this air is substantially and chemically different from general tropospheric air and what happens as a result from the perspective of atmospheric chemistry and environmental science. The surface in mountainous areas has a similar height to $700 \mathrm{hPa}$ or so. Therefore, there has been a growing number of publications in which destination sites are in mountainous areas, in particular, in the Tibetan Plateau or its vicinity (e.g., Cristofanelli et al., 2010; Chen et al., 2011; Bracci et al., 2012; Chen et al., 2013, 2016; Ma et al., 2014; Ohja et al., 2014). Backward trajectory analysis suggests that the position of the subtropical jet stream could play an important role in deep stratospheric intrusions (Cristofanelli et al., 2010). Impact of deep STT to atmospheric composition of not only ozone but also other atmospheric tracers has been investigated at highlying sites (Trickl et al., 2010; Bracci et al., 2012). However, since the top of the mixed layer sometimes reaches more than 9000 m a.s.l. over the Tibetan Plateau (Chen et al., 2013), features of STT and descent routes from the stratosphere are much different from those over non-mountainous areas.

In non-mountainous areas on the other hand, systematic deepest STT studies have not been conducted thus far. At most, studies have discussed whether surface ozone is influenced by stratospheric ozone. Lin et al. (2012) showed that a global high-resolution chemistry-climate model can capture the observed layered features and sharp ozone gradients of deep stratospheric intrusions. These stratospheric intrusions led to elevated background ozone concentrations. Ambrose et al. (2011), Lefohn et al. (2012), Langford et al. (2012), Yates et al. (2013), Langford et al. (2015), and Lin et al. (2015) also investigated influences of STT to elevated ozone concentrations at several stations in the USA by using numerical models and aircraft and lidar observations. Identifying the descent down to the surface is a challenge. However, in these studies, the identification is insufficient, because air parcels originally in the stratosphere were not sequentially traced to the surface. Moreover, an indicator that directly demonstrated stratospheric intrusions to the surface was not used; therefore, it is difficult to judge whether the result was actually influenced by stratospheric air.

In this context, the present study investigates the descending air from the stratosphere to Earth's surface in a nonmountainous area. This study aims at answering the following questions: can stratospheric air rapidly descend to the surface? If so, what route does it follow, and what mechanism is it based on?

The problem is to find a way how such a study can be conducted. It looks simple on the surface, because we can calculate forward trajectories of parcels originating in the stratosphere with the destination being Earth's surface, i.e., an extension of Wernli and Bourqui (2002), or backward trajectories in which the parcels originate at Earth's surface with the destination being the stratosphere. However, doing so is difficult: a trajectory between the stratosphere and surface has a longer completion time, as is clearly shown later. More importantly, many calculated trajectories starting in the upper troposphere/lower stratosphere reach $700 \mathrm{hPa}$ but very few reach the Earth's surface itself - that is, most trajectories cannot reach the surface. In short, even if numerous trajectories are calculated, nearly all such calculations are of no use.

Thus, an appropriate indicator is required for effective trajectory calculations. In this study, we used the concentration of beryllium $7\left({ }^{7} \mathrm{Be}\right)$ as an indicator; ${ }^{7} \mathrm{Be}$ is a radioactive isotope, most of which (about $70 \%$ ) is produced in the stratosphere (the remaining $30 \%$ in the upper troposphere) by cosmic-ray spallation (Masarik and Beer, 1999; Nagai et al., 2000; Land and Feichter, 2003; Usoskin and Kovaltsov, 2008; Bezuglov et al., 2012), and it has a half-life as short as 53 days. Therefore, observations of high concentrations of ${ }^{7} \mathrm{Be}$ on the surface are direct indications of phenomena in which stratospheric air (or near-stratospheric air) promptly descends to the surface, because ${ }^{7} \mathrm{Be}$ decays during extended air travel durations in the troposphere, where high concentrations cannot be sustained. The two characteristics of stratospheric origin and short half-life time are unique to ${ }^{7} \mathrm{Be}$ and are not provided by other substances. By setting the starting points and times of backward trajectories to the point at which high concentrations of ${ }^{7} \mathrm{Be}$ are observed, trajectory calculations can be conducted effectively. Note that, because high concentrations of ${ }^{7} \mathrm{Be}$ do not automatically guarantee 
stratospheric (or near-stratospheric) origins, other criteria are put together, as described in Sect. 3.

Numerous STT studies have employed ${ }^{7} \mathrm{Be}$ concentrations. However, when ${ }^{7} \mathrm{Be}$ is used alone, rapid descent might be missed because ${ }^{7} \mathrm{Be}$ concentrations become low when wet scavenging is performed on descending air (Gerasopoulos et al., 2001). Instead, the ratio of ${ }^{10} \mathrm{Be}$ to ${ }^{7} \mathrm{Be}$ is used (e.g., Raisbeck et al., 1981): ${ }^{10} \mathrm{Be}$ is also a radioactive isotope that is mainly produced in the stratosphere; however, its half-life time is $1.39 \times 10^{6}$ years, which is significantly longer. Thus, even when subjected to wet scavenging, small values of this ratio indicate rapid descent. However, for the purpose of this study, it suffices to use ${ }^{7} \mathrm{Be}$ concentrations alone. This is because the objective is not to obtain all STT events and their statistical characteristics; instead, it suffices to consider a few tens of fast descent events. Missing some fast descents is not a weak point for the present purpose. In addition, as high concentrations of ${ }^{7} \mathrm{Be}$ are indicative of an absence of wet scavenging, it is simpler to trace backward trajectories in such cases, which is preferable for the present purpose.

In previous studies using ${ }^{7} \mathrm{Be}$, its concentration was most often measured at mountain observatories in East Asia and Europe or through aircraft observations, and the STT was then studied using these data. In East Asia, Tsutsumi et al. (1998) measured the ozone and ${ }^{7} \mathrm{Be}$ concentrations at Mt. Fuji (3776 ma.s.1.) in Japan and found that both concentrations became large at some times. Backward trajectory analysis beginning at these times indicated the intrusion of a stratosphere-origin air mass into the troposphere. Zheng et al. (2011) observed ${ }^{10} \mathrm{Be} /{ }^{7} \mathrm{Be}$ on the Tibetan Plateau and found that it exhibited marked seasonal variations. By aircraft observations, Jordan et al. (2003) produced a large data set of ${ }^{7} \mathrm{Be}$ concentrations. Upon analyzing this data set, they inferred some STT mechanisms, including tropopause folds and mixing associated with subtropical jets. In Europe, Elbern et al. (1997) identified many stratospheric intrusion events at the two European summits by using ${ }^{7} \mathrm{Be}$ and ozone concentrations. Stohl et al. (2000) combined ozone and ${ }^{7} \mathrm{Be}$ measurements on the Alps and northern Apennines and numerical-model calculations, investigating stratospheric intrusions. In the project titled Influence of Stratosphere-Troposphere Exchange in a Changing Climate on Atmospheric Transport and Oxidation Capacity (STACCATO), combined measurements of ${ }^{10} \mathrm{Be}$ and ${ }^{7} \mathrm{Be}$ concentrations were carried out regularly during the course of a full year at two high-altitude stations (Stohl et al., 2003). In addition, the STT was studied on an integrated basis using several methods including numerical simulation. Zanis et al. (2003) showed that the ${ }^{10} \mathrm{Be} /{ }^{7} \mathrm{Be}$ ratio is generally high under synoptic situations related to stratospheric intrusion episodes. Cristofanelli et al. (2003) and Usoskin et al. (2009) compared numerical model results with measured ${ }^{7} \mathrm{Be}$ concentrations at the surface, which revealed that all models captured the general behavior of the intrusion event. Cristofanelli et al. (2006) evaluated effects of stratospheric intrusions to sur- face ozone and ${ }^{7} \mathrm{Be}$ concentrations at the Mt. Cimone station (2165 ma.s.1.) by calculating backward trajectories. By using ${ }^{7} \mathrm{Be}$ and $\mathrm{H}_{2} \mathrm{O}$ thresholds, Trickl et al. (2014) examined deep intrusions of stratospheric air reaching at the Zugspitze summit (2962 ma.s.1.) in Germany. In summation, although the usefulness of ${ }^{7} \mathrm{Be}$ observations and numerical models for STT studies has been confirmed, no studies have focused on the access of stratospheric air to the surface other than that in mountainous areas, nor have its mechanisms been examined.

From the very start, it is impossible to present mechanisms from the aforementioned ${ }^{7} \mathrm{Be}$ observational data, except one datum at the Mt. Cimone station (Cristofanelli et al., 2006; Tositti et al., 2014). That is, in these data, sampling periods are long (1 week or so) or observational periods are short (1 year or less). Data from short sampling periods (1 day or so) are required to narrow down the starting times of trajectory calculations, and extended consecutive observations are needed to provide generality to the proposed mechanisms. On the other hand, we have the necessary data in a nonmountainous area, which include short sampling periods and extended consecutive observations, as presented in Sect. 2. Thus, we can effectively perform numerous calculations of backward trajectories.

The remainder of this paper is organized as follows. In Sect. 2, the observational results of ${ }^{7} \mathrm{Be}$ concentrations are shown. In Sect. 3, high-concentration ${ }^{7} \mathrm{Be}$ events are extracted, and on the basis of this information, we propose a method for obtaining rapid descent routes using backward trajectories. In Sect. 4, we present the results and clarify the routes from the stratosphere to the surface. Moreover, the mechanism for fast routes is presented by specifying the phenomena associated with the routes. In Sect. 5, the discussions are presented. Finally, in Sect. 6, the conclusions are provided.

\section{Observational results of ${ }^{7} \mathrm{Be}$ concentration}

${ }^{7}$ Be concentrations have been consecutively measured since 1998 (Narazaki and Fujitaka, 2009) at the Fukuoka Institute of Health and Environmental Sciences (FIHE) located in Dazaifu, Fukuoka Prefecture, Japan $\left(33.5^{\circ} \mathrm{N}, 130.5^{\circ} \mathrm{E}\right.$, 30 ma.s.l.; Fig. 1). Sampling intervals are once every 1 to 5 days before March 2011 and nearly every day since then. However, measurements were not available between 6 October and 19 November 2014, when the buildings were being retrofitted for earthquake resistance. The measurement times are around 00:00 UTC (09:00 Japan Standard Time). Among previous studies, only Kikuchi et al. (2009) examined the data of ${ }^{7} \mathrm{Be}$ concentration almost daily over several years at a non-mountainous site.

The ${ }^{7}$ Be concentrations were measured as follows: aerosol samples were collected on quartz fiber paper (QR-100; $20.3 \mathrm{~cm} \times 25.4 \mathrm{~cm}$; ADVANTEC Co., Ltd.) using highvolume air samplers (HVC-1000N, HV-1000F, and HV- 


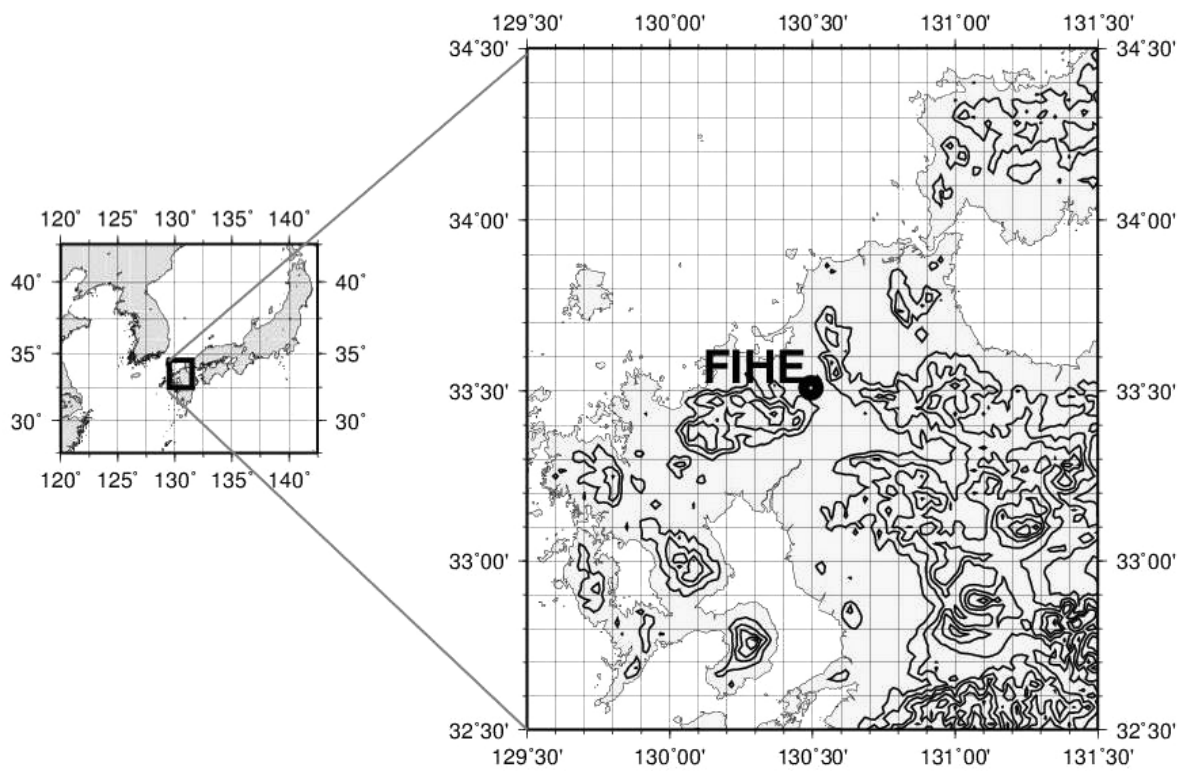

Figure 1. Map of the area near the Fukuoka Institute of Health and Environmental Sciences. Contours indicate altitude a.s.l. at intervals of $200 \mathrm{~m}$.

1000R; Shibata Science Co., Ltd.). The flow rate was $1000 \mathrm{~L} \mathrm{~min}^{-1}$, and the integrated air volume was 1440$5500 \mathrm{~m}^{3}$ per sample. The paper collecting the aerosol was folded with the sampling side inside to create 12 sheets that were then punched through by a punch with a diameter of $48 \mathrm{~mm}$. To reduce their volume, the 12 sheets of paper were then pressurized with a force of about $10 \mathrm{t}$ by a pressure machine to form a disk of $2 \mathrm{~mm}$ thickness. The ${ }^{7} \mathrm{Be}$ activity was measured using a high-purity germanium detector system (Canberra). The ${ }^{7} \mathrm{Be}$ concentrations were obtained after being adjusted to the sampling dates on which the radioactivity decayed with the half-life time of ${ }^{7} \mathrm{Be}$. Error of ${ }^{7} \mathrm{Be}$ concentrations is typically $5 \%$.

The analysis period is 6 years from 2009 to 2014. This period is sufficiently long to capture statistical characteristics with a high degree of confidence.

Figure 2 shows observational results of ${ }^{7} \mathrm{Be}$ concentrations. The measurement period is from April 2011, when the measurement was changed to once per day, to September 2014, prior to the earthquake-resistant retrofitting. The concentrations are quite low during summer, suggesting large seasonal variations. This result is the same as those reported by Megumi et al. (2000) and Kikuchi et al. (2009) ${ }^{1}$, who presented observational results for other locations in Japan. However, Narazaki and Fujitaka (2009) also indicated several observational locations at which double peaks in spring and autumn are prominent.

\footnotetext{
${ }^{1}$ Kikuchi et al. (2009) reported the existence of double peaks in spring and autumn. However, the concentrations in winter are nearly the same as those in spring and autumn, as far as we can see the figure.
}

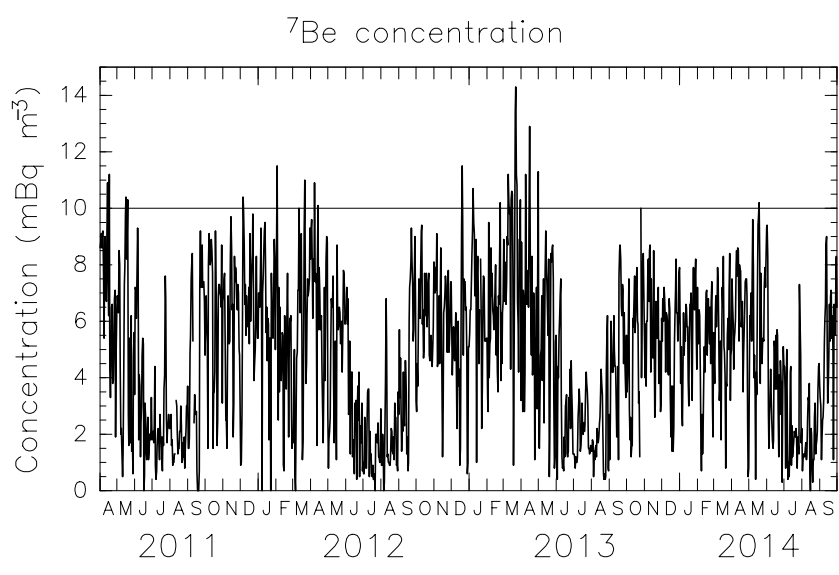

Figure 2. Time change of ${ }^{7} \mathrm{Be}$ concentrations from 1 April 2011 to 30 September 2014 . The ordinate is ${ }^{7} \mathrm{Be}$ concentration (unit: $\mathrm{mBq} \mathrm{m}^{-3}$ ), and the abscissa is time. The horizontal line indicates $10 \mathrm{mBqm}^{-3}$.

Table 1 shows the seasonal averages and standard deviations (SDs) of ${ }^{7} \mathrm{Be}$ concentrations. Because the time resolution of the measurement is not constant, these values are calculated by considering the weight of time. DJF represents December, January, and February; MAM, March, April, and May; JJA, June, July, and August; and SON, September, October, and November. In the following, DJF, MAM, JJA, and SON are referred to as winter, spring, summer, and autumn, respectively, for simplicity. The averages are arranged by spring, winter, autumn, and summer in order of magnitude. However, because the differences are small except for summer, we consider the averages in spring, winter, and autumn 
Table 1. Averages and standard deviations (SD) of seasonal ${ }^{7} \mathrm{Be}$ concentrations in $\mathrm{mBq} \mathrm{m}^{-3}$. "Days" denotes the total days of measurement. They are not integers because measurement times are not just 00:00 UTC. For instance, when measurement times are 00:00 UTC on one day and 01:00 UTC on the following day, $(1+$ $1 / 24$ ) days are added. The much lesser number of measurement days in SON than in the other seasons is attributed to the missing data owing to the earthquake-resistant retrofitting in 2014.

\begin{tabular}{lrrr}
\hline & Average & SD & Days \\
\hline Total & 5.20 & 2.19 & 2133.5 \\
\hline DJF & 6.08 & 1.96 & 533.3 \\
MAM & 6.33 & 2.60 & 547.1 \\
JJA & 2.67 & 1.90 & 554.8 \\
SON & 5.83 & 2.22 & 498.3 \\
\hline
\end{tabular}

to be nearly identical. The SDs are largest in spring, indicating a large time variation.

Peaks of ${ }^{7} \mathrm{Be}$ concentrations are observed in various seasons worldwide, and many studies have aimed at understanding how these peaks are determined (e.g., Feely et al., 1989; Buraeva et al., 2007). However, the focus of the present study does not require the identification of the factors determining seasonal variations.

\section{Method for obtaining fast descent routes}

\subsection{Method and data}

In this study, ${ }^{7} \mathrm{Be}$ concentrations of more than $10 \mathrm{mBqm}^{-3}$ are defined as high-concentration events. This value is more than the average $+2 \mathrm{SD}\left(9.58 \mathrm{mBq} \mathrm{m}^{-3}\right)$ from Table 1 ; therefore, this value is statistically significant (see also Fig. 2). Because the measurement time (starting and closing times of measurement) is around 00:00 UTC, high-concentration days are used almost interchangeably with high-concentration events.

At certain times on these days, it is highly possible that parcels originating from within or near the stratosphere arrive in Fukuoka, where Fukuoka refers to the area around FIHE in this study. We then calculated the backward trajectories from the five time points of 00:00, 06:00, 12:00, 18:00, and 24:00 UTC (i.e., 00:00 on the following day) on these days. These times are the output times for the Japanese 55-year Reanalysis (JRA-55) data. More specifically, the trajectories were traced from 1734 starting points near FIHE, which are on six levels (in intervals of $25 \mathrm{~m}$ from 25 to $150 \mathrm{~m}$ altitude above the surface) and $17 \times 17$ grid points with a grid interval of $5 \mathrm{~km}$ centered at FIHE on one altitude surface. Numerous starting points are used for three reasons. First, the ${ }^{7} \mathrm{Be}$ concentration at FIHE is not necessarily determined by one trajectory over FIHE but by many trajectories near FIHE, because diffusion is strong in the boundary layer. Second, the amount of air descending from the stratosphere can be evaluated from numerous trajectories. Third, to form clear statistical characteristics, numerous trajectories are needed. If the trajectories reach the stratosphere or its vicinity within 10 days, they are considered to exhibit fast descent routes from the stratosphere to Fukuoka. Moreover, we can present the mechanism of fast descent routes by specifying the meteorological phenomena occurring at these times.

The parcel positions were calculated by using the fourthorder Runge-Kutta scheme; the integration time step and period were $10 \mathrm{~min}$ and 10 days, respectively, and the wind, which advects the parcels, was interpolated linearly in time and in the vertical direction and by cubic splines in the horizontal plane. We assume that parcels were transported latitudinally and longitudinally by the meridional and zonal wind components, respectively. However, because such calculations cannot be conducted near the pole, they were performed in the following manner: first, the near-pole area was defined as the area north of $89.57^{\circ} \mathrm{N}$, which is the northernmost Gaussian latitude. This spherical area was approximated as a plane, and the zonal and meridional winds were converted to the two components perpendicular to each other within this plane. The parcels were assumed to be advected by these wind components. The vertical motion is expressed by the vertical $p$ velocity. Therefore, parcel positions were first calculated in the pressure value, and then, by using the pressure and height data, the height value was obtained.

The model-grid data for the JRA-55 served as the meteorological data to trace the backward trajectories (Kobayashi et al. 2015). Moreover, we used the isentropic and pressure-level data to specify the phenomena associated with the descent routes. In the model-grid data, the horizontal resolution is about $0.5625^{\circ}(640 \times 320$ Gaussian grids $)$ except near the poles, where the data grids are reduced. The number of vertical levels is 60 with a top level of about $10 \mathrm{~Pa}$. The pressure-level data have a resolution of $1.25^{\circ}$ in the longitudinal and latitudinal directions and 37 vertical levels, of which 23 levels below $200 \mathrm{hPa}$ were used for the analysis. In the isentropic data, the two data sets in which the resolutions are the same as the model-grid data and $1.25^{\circ}$ were used. The number of vertical levels is 21 , of which only eight levels below the $340 \mathrm{~K}$ surface were used (the lowest level is the $270 \mathrm{~K}$ surface).

High-concentration events of ${ }^{7} \mathrm{Be}$ are shown in the second row in Table 2. The total number of events was 44, covering 56 days. However, we should be cautious that the sampling intervals, i.e., averaging periods, are not constant, because a longer averaging period relates to statistically fewer high-concentration days. Therefore, prior to March 2011, the high-concentration days may be underestimated. However, this difference is not considered in the present study.

Seasonal variations show that high-concentration days are predominant in spring (March, April, and May), totaling 41 days $(73 \%)$. Two events in summer, on 1 and 2 June, should essentially be regarded as May events. If these are 
Table 2. Numbers of seasonal and monthly high-concentration (HC) events of ${ }^{7} \mathrm{Be}$ and $\hat{z}_{\mathrm{a}}$ maximum events. Because the sampling intervals are not necessarily 1 day, the number of days is equal to or more than the number of events. The meanings of $\hat{z}_{\mathrm{a}}$ and $\hat{z}_{1}$ are referred to in the text. The bottom four rows indicate classifications of the highest reached altitude in each event.

\begin{tabular}{lccccccc}
\hline & DJF & March & April & May & JJA & SON & Total \\
\hline HC events (number of days) & $7(9)$ & $16(18)$ & $12(12)$ & $5(11)$ & $2(2)$ & $2(4)$ & $44(56)$ \\
$\hat{z}_{\mathrm{a}}$ maximum events & 7 & 15 & 12 & 9 & 1 & 2 & 47 \\
\hline$\hat{z}_{1} \geq 10000 \mathrm{~m}$ & 1 & 1 & 1 & 1 & 1 & 0 & 5 \\
$9000 \leq \hat{z}_{1}<10000 \mathrm{~m}$ & 0 & 2 & 3 & 2 & 1 & 1 & 9 \\
$8000 \leq \hat{z}_{1}<9000 \mathrm{~m}$ & 2 & 6 & 4 & 6 & 0 & 1 & 19 \\
\hline$\hat{z}_{1}<8000 \mathrm{~m}$ & 4 & 6 & 4 & 0 & 0 & 0 & 14 \\
\hline
\end{tabular}

added to spring events, the appearance ratio in spring becomes $77 \%$. Following spring, seven winter events (9 days) are found. As the averaged concentrations are nearly the same among winter, spring, and autumn, as observed previously, this means that the rapid descent routes from the stratosphere to Fukuoka occur frequently only in spring. The reason for such a large number of high-concentration days in spring is discussed in Sect. 5.

\subsection{Case selection for analysis}

As stated above, backward trajectories were traced from the five times over one day in general. Thus, all of the traced times were superficially 56 days $\times 5(=280)$ but strictly 260 , because, for instance, in a case of two consecutive highconcentration days, traced times are not 10 but 9 and so on. However, all of these times were not objectives for analysis, because all trajectories could not originate in altitude ranges other than the stratosphere and its adjacent region. Therefore, in this subsection, we simply explain how to select cases for analysis. The detail is described in the Supplement.

First, two indices are defined. The first is $\hat{z}_{1}$ defined as follows. Let $\hat{z}_{i}(i=1, \ldots, 1734)$ be the highest altitude reached in each trajectory, where $i$ is a suffix in order of the altitude. Therefore, $\hat{z}_{1}$ is the highest altitude among all 1734 trajectories. Because this value is, of course, one index to determine the parcel origin, $\hat{z}_{1}$ is the first index used to select object times for analysis. However, the ${ }^{7} \mathrm{Be}$ concentration observed at the surface does not necessarily correspond only to $\hat{z}_{1}$, because even if $\hat{z}_{1}$ is high, the ${ }^{7} \mathrm{Be}$ concentration at the surface, which is observed as somewhat of a mixture of air parcels originating from many trajectories, may not become high when all the other trajectories come from low altitudes. Then, as the second index, we use the top- $1 \%$ average, i.e., top-18 average of $\hat{z}_{i}$. This value is represented as $\hat{z}_{\mathrm{a}}$. That is,

$\hat{z}_{\mathrm{a}}=\frac{1}{N_{\mathrm{a}}} \sum_{i=1}^{N_{\mathrm{a}}} \hat{z}_{i}$

where $N_{\mathrm{a}}=18$. Objects for analysis are basically selected as the time when $\hat{z}_{\mathrm{a}}$ is the maximum and $\hat{z}_{1} \geq 8000 \mathrm{~m}$.
Based on the maximum of $\hat{z}_{\mathrm{a}}$ only, 47 cases are selected, as shown in the third row of Table 2 . The maxima of the highest reached altitude, $\hat{z}_{1}$, for these 47 cases are all more than $6000 \mathrm{~m}$. Thus, it is evidenced that the high concentration of ${ }^{7} \mathrm{Be}$ is originated from the upper troposphere/lower stratosphere. However, in 14 cases among them, $\hat{z}_{1}$ is less than $8000 \mathrm{~m}$; the remaining 33 cases, which are considered as reaching the stratosphere or adjacent regions, are chosen as objects for analysis. Among the objects for analysis, $\hat{z}_{1}$ of more than 10000 and $9000 \mathrm{~m}$ is attained in 5 and 14 cases, respectively. Even in the 14 cases of $\hat{z}_{1}<8000 \mathrm{~m}$, if the tracing times of backward trajectories were extended, the trajectories could reach altitudes higher than $8000 \mathrm{~m}$. However, this type of research is beyond the scope of the present study.

The details of the 33 cases are shown in the Supplement. The case numbers are assigned in chronological order. The maxima of the potential vorticity (PV) of parcels on trajectories have all more than $2 \mathrm{PVU}\left(10^{-6} \mathrm{~m}^{2} \mathrm{~s}^{-1} \mathrm{~K} \mathrm{~kg}^{-1}\right)$; the minimum is $2.35 \mathrm{PVU}$ and 30 cases exceed $3 \mathrm{PVU}$. Because $2 \mathrm{PVU}$ is said to be an index of stratospheric air (e.g., Hoskins et al., 1985; Wernli and Bourqui, 2002; Sprenger and Wernli, 2003), all cases have the characteristic of stratospheric air in terms of PV. As PV is not well conserved (not shown), the Lagrangian time changes of PV are not mentioned in the following analyses.

\section{Results}

In this section, the terms "top $1 \%$ " and "top $25 \%$ " are frequently used. Their meanings are the same as those in the previous section, i.e., top 1 and $25 \%$ of $\hat{z}_{i}$, the highest reached altitude, of each trajectory. Furthermore, $z_{i}(t)$ is defined as the trajectory with $i$ th highest altitude, which is a function of time, $t$. For simplicity, $\hat{z}_{i}$ or the highest reached altitude is omitted hereafter.

\subsection{Overall characteristics}

Figure 3 shows top- $1 \%$ averaged trajectories for 2 days from their highest altitudes for all the 33 cases. The averages of 

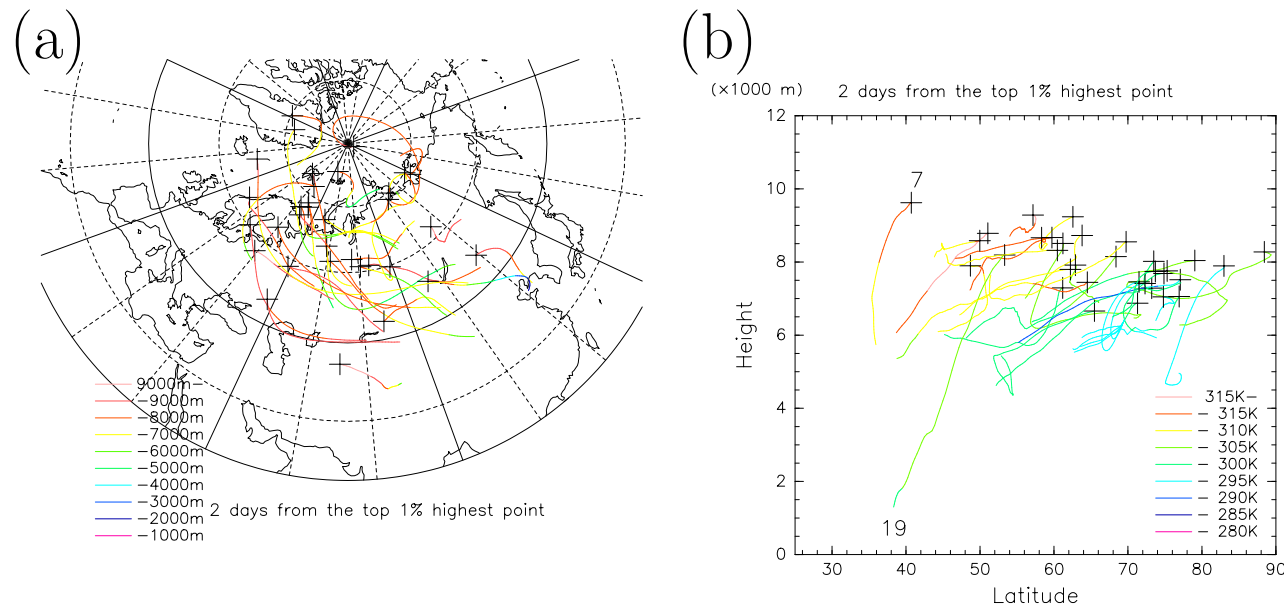

Figure 3. Top-1\% averaged trajectories for 2 days from their highest altitude. (a) Horizontal component of the trajectories and (b) trajectories in the latitude-vertical section for all 33 cases are shown. Colors indicate altitudes in panel (a) and potential temperature in panel (b). The symbol + shows the position of the highest altitude of each top- $1 \%$ averaged trajectory. The two numerals, 7 and 19 , are the case numbers.

latitude and longitude were not obtained as the simple arithmetic averages of latitude and longitude but as averages of points on a sphere. The average in altitude was

$\bar{z}(t)=\frac{1}{N_{\mathrm{a}}} \sum_{i=1}^{N_{\mathrm{a}}} z_{i}(t)$

The highest altitude in the average trajectory is the maximum of $\bar{z}(t)$. This value is generally smaller than $\hat{z}_{\mathrm{a}}$. If the top- $1 \%$ trajectories vary widely among each other, the average trajectory is meaningless. However, because such cases are few, we consider that the overall features of descent routes can be captured.

Figure 3a shows that the longitudes of the trajectories vary among cases and do not have a strong tendency, although most trajectories attain the highest altitude in the eastern hemisphere. Conversely, trajectories in Fig. 3b show systematic motion in latitude and altitude. That is, the highest altitudes are located at high latitudes for many trajectories, and the altitudes lower as one moves to midlatitudes. More specifically, with the exception of case 7, all cases attain their highest altitudes north of $45^{\circ} \mathrm{N}$, and 25 cases attain them north of $60^{\circ} \mathrm{N}$, i.e., in high latitudes. Thus, the routes from high latitudes are the main descent routes. The clarification of this mechanism is the most important task in this study. Figure $3 \mathrm{~b}$ shows that parcels lower the altitude while conserving their potential temperature in many cases. However, in case 7 and in a few other cases, the potential temperature is changed. Also in this respect, the characteristics of case 7 differ from those of many other cases. Case 19 shows a large descent of $6892 \mathrm{~m}$ for 2 days, with $4659 \mathrm{~m}$ recorded on the first day. The cause of this rapid descent is investigated in Sect. 4.2.3.

To pursue the route from high latitudes, we further examine the 25 cases in which the highest altitude is attained north

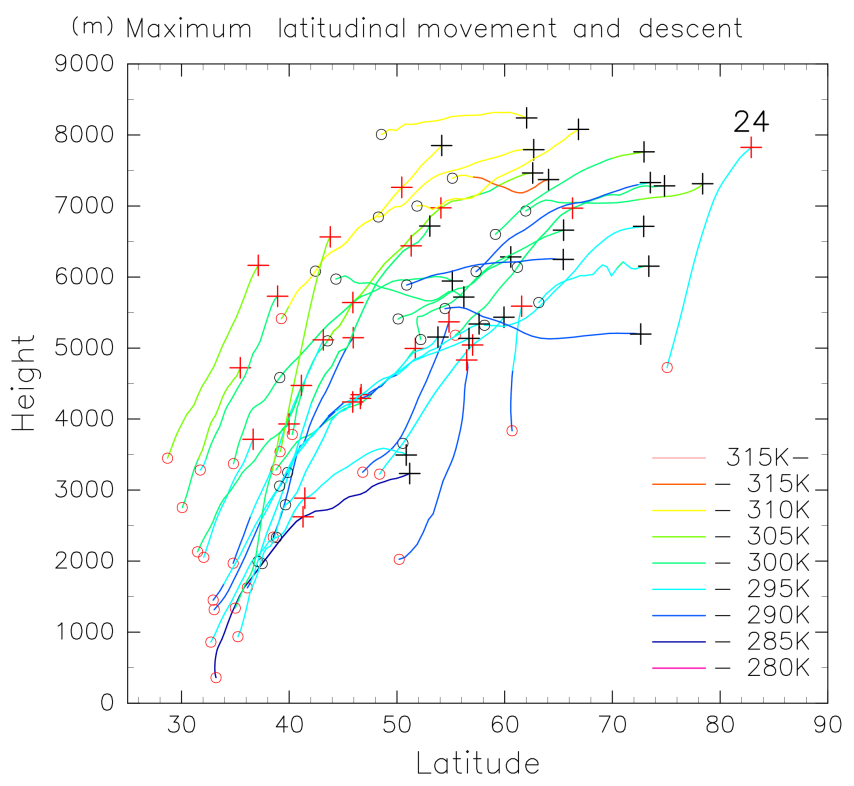

Figure 4. Paths showing the maximum latitudinal movement and maximum descent per day. The black (red) symbols of + and $\circ$ indicate the starting and final positions, respectively, for the latitudinal movement (descent). The 25 cases showing the highest altitude north of $60^{\circ} \mathrm{N}$ are illustrated. The line color represents the potential temperature. The numeral (24) attached to the descent route shows the case number.

of $60^{\circ} \mathrm{N}$. Figure 4 shows the paths of the maximum latitudinal movement and maximum descent per day for these 25 cases. The maximum latitudinal movement per day means that moving distance per day in the southward direction is the maximum along a trajectory. The maximum descent per day has a similar meaning. Table 3 presents the times when these values are reached, along with the highest altitude, as 
Table 3. The time from the beginning of backward trajectories to the point of highest altitude $\left(t_{\mathrm{a}}\right)$, the start time of maximum latitudinal movement per day $\left(t_{\mathrm{m}}\right)$, the start time of the largest descent per day $\left(t_{\mathrm{d}}\right)$, and the values of $t_{\mathrm{a}}-t_{\mathrm{m}}$ and $t_{\mathrm{m}}-t_{\mathrm{d}}$ with confidence intervals of $99 \%$ are added. All the units are in hours. These values are shown for the 25 cases attaining the highest altitude north of $60^{\circ} \mathrm{N}$.

\begin{tabular}{ccccc}
\hline $\begin{array}{c}\text { Maximum altitude } \\
\left(t_{\mathrm{a}}\right)\end{array}$ & $\begin{array}{c}\text { Latitudinal movement } \\
\left(t_{\mathrm{m}}\right)\end{array}$ & $\begin{array}{c}\text { Descent } \\
\left(t_{\mathrm{d}}\right)\end{array}$ & $t_{\mathrm{a}}-t_{\mathrm{m}}$ & $t_{\mathrm{m}}-t_{\mathrm{d}}$ \\
\hline 211.7 & 157.4 & 115.0 & $54.2 \pm 27.5$ & $42.4 \pm 24.7$ \\
\hline
\end{tabular}

the time from the starting time of backward trajectories. In Fig. 4, the maximum-descent paths (lines terminated by red symbols) are generally located at the low-latitude side, compared with the paths of the maximum latitudinal movement (black symbols), which indicates that the large latitudinal movement is followed by the large descent. Furthermore, the latitudinal movement is accompanied by relatively slow descent. According to Fig. 4 and Table 3, the following processes occur in the usual time sequence (forward trajectory): first, the highest altitude is achieved (its time is denoted as $t_{\mathrm{a}}$ ). Slightly more than 2 days later, a large movement in the latitudinal direction begins with slow descent (start time: $t_{\mathrm{m}}$ ), and slightly little less than 2 days after that, the largest descent occurs (start time: $t_{\mathrm{d}}$ ). Because $t_{\mathrm{a}}-t_{\mathrm{m}}$ and $t_{\mathrm{m}}-t_{\mathrm{d}}$ are positive even at the edges of the confidence intervals of $99 \%$ (26.7 and $17.7 \mathrm{~h}$ ), the reversal of these times does not occur statistically. In fact, the reversal occurs only in a few cases, i.e., in three cases for $t_{\mathrm{a}}-t_{\mathrm{m}}$ (within $3 \mathrm{~h}$ for all three cases), and only in one case (case 24) for $t_{\mathrm{m}}-t_{\mathrm{d}}$ among all 25 cases.

Figure 5 shows the top- $1 \%$ averaged trajectories for the last 2 days of travel. At a glance, these trajectories are not systematic and approach Fukuoka from all directions. The variations in height and latitude are small for 2 days, and a relatively long time is needed to finally arrive at Fukuoka at low altitudes, with the exception of three cases (cases 9, 23, and 31). These results are consistent with those in Table 3 in that it takes an average of $91 \mathrm{~h}(115.0-24.0)$ to reach the surface after the largest descent. Therefore, a long time is generally required to reach the surface from low altitudes such as $700 \mathrm{hPa}$, which is the destination given by Wernli and Bourqui (2002) and others. Thus, almost all calculations of backward and forward trajectories without an indicator would be of no use, as stated in the Introduction.

Disturbances affecting the arrival to the surface vary among cases, e.g., descending current associated with anticyclones and downward flow at the southwest side of extratropical cyclones. That is, no specific disturbance is involved in the transport of air parcels to Fukuoka; however, good matching between the parcel positions a few days prior to their arrival at Fukuoka and the disturbances is necessary.

In summary, the majority of the high-latitude routes take the following paths, with a few exceptions. First, after attaining the highest altitude, air parcels descend slightly at high latitudes, followed by large movement toward low latitudes with slow descent. Then, a large descent occurs. From low altitudes, various disturbances are attributed to the long time required for the parcels to reach finally the surface.

In the following subsection, we examine in detail the mechanism for the high-latitude route, and we analyze a few characteristic cases other than this route.

\subsection{Case studies}

\subsubsection{Descent routes from high latitudes}

As stated in the previous subsection, the main route is the descent from the high latitudes north of $60^{\circ} \mathrm{N}$. The mechanism of this route is clarified first.

Case 1 (starting time of 18:00 UTC, 17 March 2009) is considered typical. Figure 6 shows the top- $1 \%$ trajectories. With a few exceptions, the trajectories attain their highest altitudes about 10 days before the starting time of the backward trajectories (18:00 UTC, 7 March). Afterwards, air parcels descend to about $7000 \mathrm{~m}$ at $65-75^{\circ} \mathrm{N}$ and then move to midlatitudes with slow descent from about 18:00 UTC, 10 March. Subsequently, they descend rapidly, and a long time is required to reach the surface from about $2500 \mathrm{~m}$. In short, the features represented by this case are typical of the descent route from high latitudes.

The first inspection is devoted to the mechanism of the descent from the highest altitude. Figure 7 shows the $300 \mathrm{hPa}$ surface at 18:00 UTC, 7 March (the last time of backward trajectories), and the vertical section of $\mathrm{PV}$ along $45^{\circ} \mathrm{E} 6 \mathrm{~h}$ later. The air parcels on the trajectories are also plotted to reveal their relationship with the trajectory. This time is chosen to represent the point at which the parcels on the trajectories record the highest altitude. Near $65^{\circ} \mathrm{N}$ in Fig. $7 \mathrm{~b}$, the area with large PV hangs deeply into the troposphere. Because this feature is also seen in a longitude-vertical section (not shown), this phenomenon is considered a tropopause fold. Air parcels with large PV exist near this region, and weak subsidence is dominant at the northeast side of this disturbance. The parcels at high altitudes descend by this subsidence (Fig. 7b) ${ }^{2}$. This is the mechanism of the initial descent from the stratosphere.

Next, the mechanism of the southward movement with slow descent is revealed. Figure 8 shows the disturbance involved in the movement of parcels at 18:00 UTC, 10 March,

\footnotetext{
${ }^{2}$ Ascending parcels are those entering near $45^{\circ} \mathrm{E}$ from the west, as seen in Fig. 6a.
} 

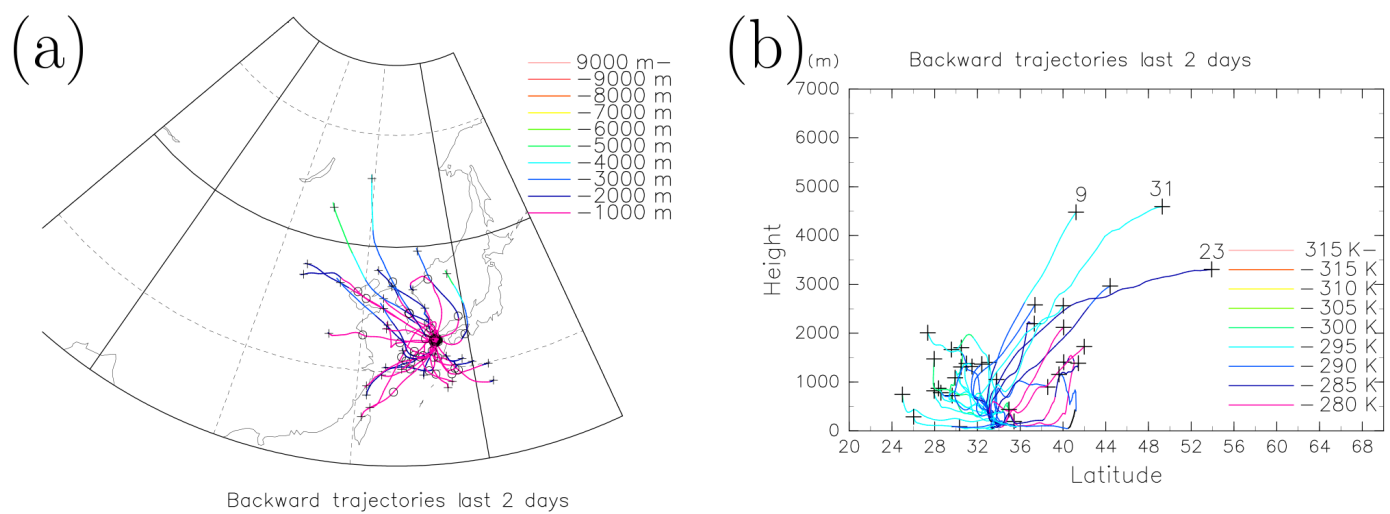

Figure 5. Top-1\% averaged trajectories for the last 2 days of travel. (a) Horizontal component of the trajectories and (b) trajectories in the latitude-vertical section for all 33 cases are shown. The colors are the same as those in Fig. 3 . The + symbol indicates the position before 2 days of object times for analysis. The three numerals $(9,23$, and 31$)$ in panel (b) indicate the case numbers.

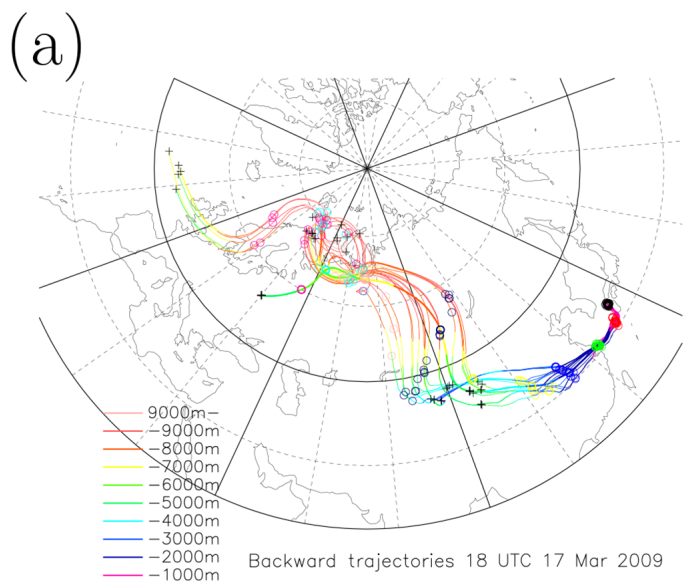

(b)

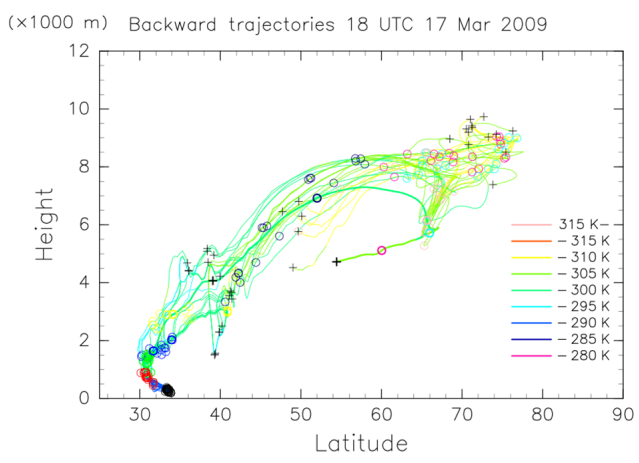

Figure 6. Backward trajectories starting at 18:00 UTC, 17 March 2009 (case 1). (a) Horizontal component of the routes and (b) routes in the latitude-vertical section of the top- $1 \%$ trajectories (18 lines) and the top- $25 \%$ averaged trajectory (thick line) are shown. The colors are the same as those in Fig. 3. The o symbol indicates positions at each $24 \mathrm{~h}$ interval, whereas the + symbol shows the fifth day and the last. The difference in days is represented by different colors.

when the southward movement begins, and at 18:00 UTC, 11 March, 1 day afterwards. It is clear that parcels are located on the rear side of a developed trough accompanied by strong southward wind. At 18:00 UTC, 11 March, the trough develops further, as indicated by the change in the tilt of the trough axis from N-NE to S-SW. The slow descent is closely related to the downward inclination to the south of the isentropic surface: Fig. 9a shows the height and wind at the $300 \mathrm{~K}$ isentropic surface at the same time as that in Fig. 8b. The height decreases toward the south so that parcels necessarily descend with the southward movement, if the potential temperature is conserved. In fact, Fig. $6 \mathrm{~b}$ reveals that conservation is achieved.

The rapid descent can be attributed to extension of the southward movement. At the southern edge of the trough, the height on the isentropic surface decreases dramatically (Fig. 9). In the case of weak troughs, streamlines could head north and upward after turning near the southern edge. In fact, we calculated forward trajectories in the case of weak troughs, confirming such movement (not shown). However, in this case, the trough axis indicates the tilt from N-NE to S-SW (Fig. 8b); therefore, the parcels are transported in a different direction from the moving direction of the system. Thus, the parcels cannot move along with the system; that is, they cannot turn around the southern edge of the trough, and the altitudes of the parcels decrease dramatically (Figs. 9b and 6b). This irreversible process is closely related to the filamentation of the PV, as shown in Fig. 9b (Hoskins et al., 1985). When considering this event at a constant pressure level, we see that strong downward flow is dominant, and parcels descend under this flow, as shown near $120^{\circ} \mathrm{E}$ in Fig. 10. Subsequently, the parcels lag far behind the trough system and drift at low altitudes (not shown). 

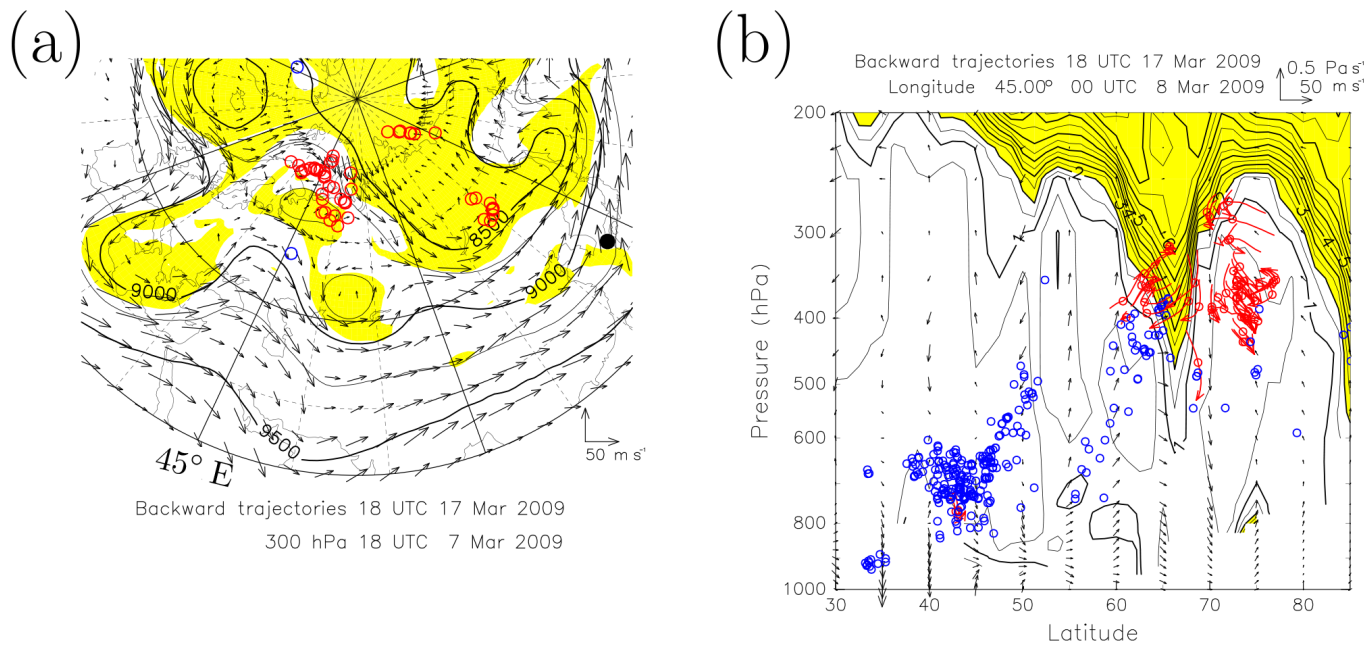

Figure 7. (a) $300 \mathrm{hPa}$ surface map at 18:00 UTC, 7 March and (b) the latitude-vertical section along 45 $\mathrm{E}$ at 00:00 UTC, 8 March 2009. Height (contour; unit: $\mathrm{m}$ ), wind (arrow), and PV (shading) are shown in panel (a), and PV (contour and shading; unit: PVU) and meridional and vertical flow (arrow) are shown in panel (b). The ordinate in panel (b) is pressure. Yellow areas in panels (a, b) indicate areas of more than 2 PVU. The symbol o represents positions of air parcels in backward trajectories for case 1, where all parcels are plotted within a height difference of $1000 \mathrm{~m}$ in panel (a) and within a longitudinal difference of $500 \mathrm{~km}$ in panel (b). Red (blue) indicates parcels with more (less) than 2 PVU of PV. The black-filled circle in (a) indicates the position of Fukuoka. For parcels with more than $2 \mathrm{PVU}$ or less than $350 \mathrm{hPa}$, their movements between $6 \mathrm{~h}$ before and after the present time are plotted by arrows in panel (b). Flow speeds are indicated at the lower-right side in panel (a) and upper-right side in panel (b).
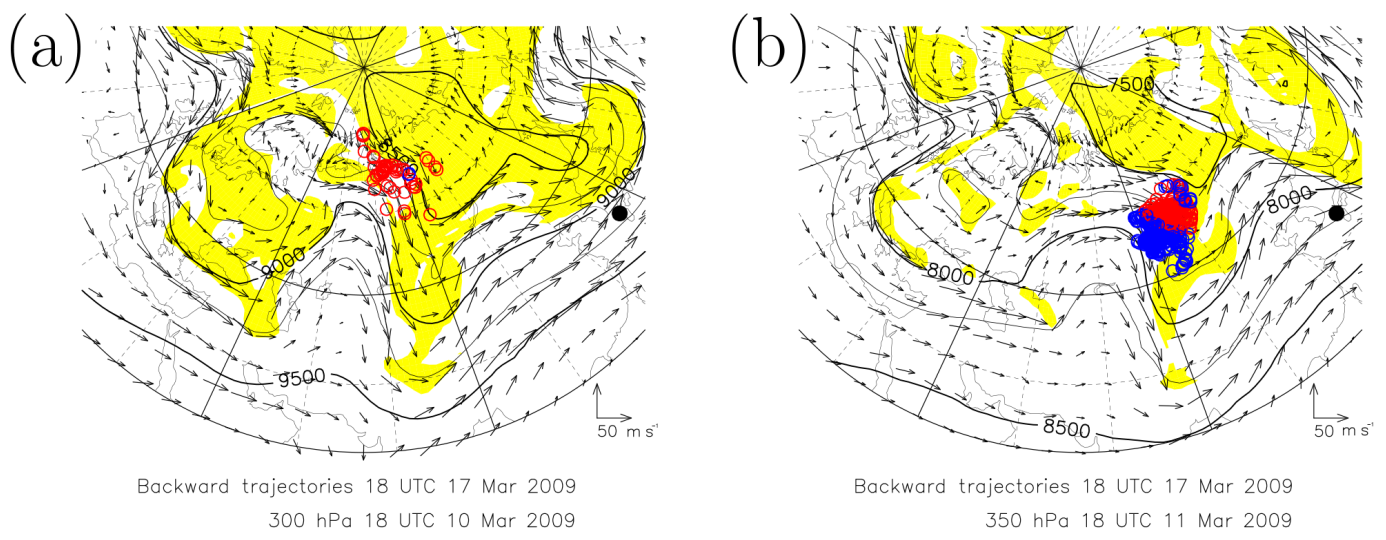

Figure 8. Same as Fig. 7a but for (a) $300 \mathrm{hPa}$ surface at 18:00 UTC, $10 \mathrm{March}$, and (b) $350 \mathrm{hPa}$ surface at 18:00 UTC, $11 \mathrm{March}$ 2009, in case 1 .

Finally, a near-surface disturbance is necessary for air parcels to reach the surface. In this case, it is a trough over the Sea of Okhotsk. Air parcels located around the subsidence region in the southern edge of the trough descend with eastward movement, arriving at Fukuoka (not shown).

It is well known that the atmospheric boundary layer (ABL) shows a clear daily variation, in which the mixed layer develops during daytime, while the stable layer is formed during nighttime. Therefore, the taking-in of air parcels above the ABL into the ABL must also show a daily variation. Then, the time (daytime and nighttime) dependency of the behavior of the air parcels on the trajectories entering the ABL is investigated. The results are shown in Fig. 11. Figure 11a illustrates that the parcels between about 500 and $1500 \mathrm{~m}$ rapidly descend at daytime, while they stay at relatively near-constant altitudes at nighttime. Figure $11 \mathrm{~b}$ indicates that the fast descent during daytime is closely related to the mixed layer (constant potential-temperature layer) extending to about $1500 \mathrm{~m}$. On the other hand, the potential temperature has a strong vertical contrast at nighttime (not shown). Thus, the air parcels above the ABL are easily taken into the ABL during daytime, while it is difficult for them to enter the ABL during nighttime. However, the mixed layer 

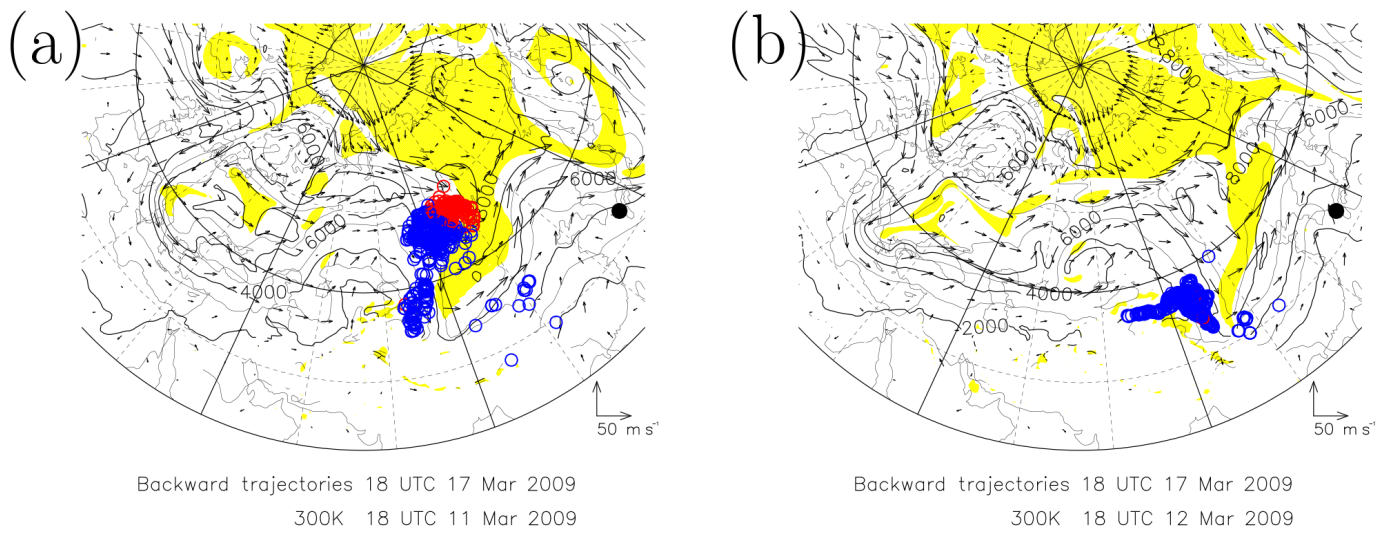

Figure 9. Same as Fig. 7a but for the $300 \mathrm{~K}$ isentropic surfaces at (a) 18:00 UTC, 11 March, and (b) 18:00 UTC, 12 March 2009 , in case 1.

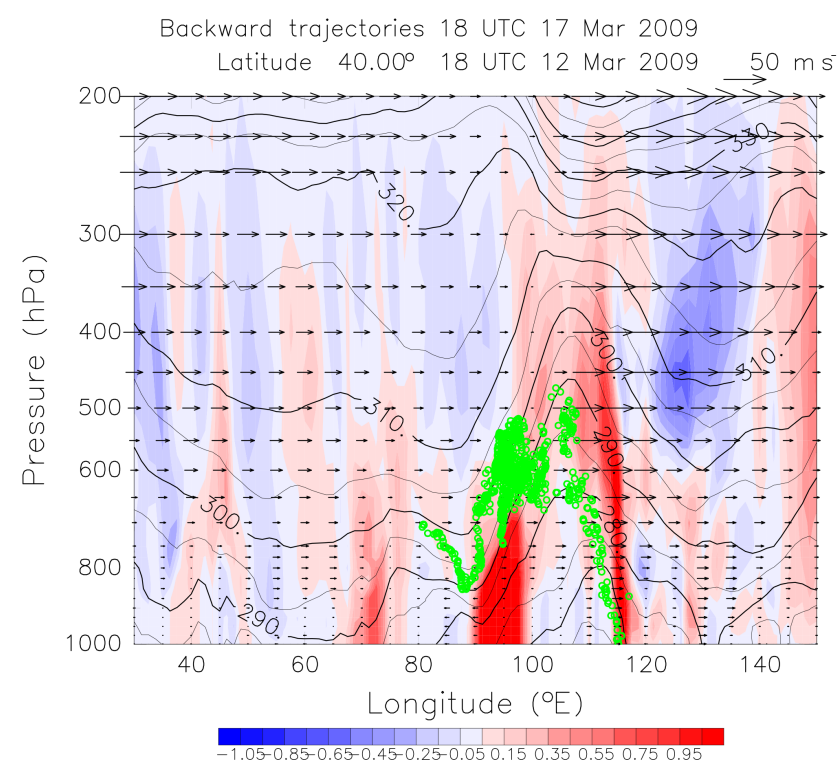

Figure 10. Longitude-vertical section along $40^{\circ} \mathrm{N}$ at 18:00 UTC, 12 March 2009. Colors indicate vertical motions (unit: $\mathrm{Pa} \mathrm{s}^{-1}$ ), and contours represent potential temperature (unit: K). Arrows show zonal wind, and their magnitudes are indicated at the upper-right side. Parcel positions within $500 \mathrm{~km}$ from $40^{\circ} \mathrm{N}$ in case 1 are plotted in green. The strong subsidence near $90^{\circ} \mathrm{E}$ may not be accurate because this area is a mountainous region.

has much smaller horizontal scales than the grid scale; a further analysis considering smaller scales is necessary.

Case 3 is presented as another case of the high-latitude route with a starting time of 06:00 UTC, 3 May 2009 (Fig. 12). Although the positions of air parcels 10 days before the starting time and behaviors at low altitudes are different from those in Fig. 6, Fig. 12b is similar to Fig. 6b. That is, it shows the sequence of the descent at the initial time, southward movement with slow descent, and rapid descent, and the potential temperature is conserved in this sequence. Although figures are not shown, closer inspection shows that the same processes as in case 1 are involved: the initial descent is associated with a tropopause fold, the southward movement is accompanied by the northerly wind at the rear side of a developed trough, and the rapid descent is associated with the large drop in height at the southern edge of the trough. The only difference is that a cutoff low is included as an irreversible process in the last process.

The other cases attaining the highest altitude at high latitudes also show similar routes with respect to the southward movement with slow descent along an isentropic surface followed by rapid descent at the southern edge of a developed trough (not shown). The behaviors of the air parcels near the ABL top during daytime and nighttime are also similar in general. Although a tropopause fold is also seen in many cases, it is not always included. In particular, in the case of $\hat{z}_{1}$ of about $8000 \mathrm{~m}$ at the initial, the parcels seem to be directly transported southward with no initial descent. Even in these cases, tropopause folds may occur before the last time of backward trajectories, but this is left as future work.

\subsubsection{Descent routes within midlatitudes}

Figure 13 shows backward trajectories starting at 18:00 UTC, 25 December 2009 (case 7), which is an example of the descent from high altitudes at midlatitudes. We can clearly see that the potential temperature is not conserved; instead, it decreases. This decrease is expected: because the potential temperature at high altitudes is high, air parcels conserving potential temperature cannot fall from those positions to the surface, where the potential temperature is low. Moreover, the top- $1 \%$ averaged route is largely different from the top- $25 \%$ averaged route. That is, the top- $1 \%$ trajectories are unique among the top- $25 \%$ trajectories; they are not representative of trajectories reaching relatively high altitudes. In these respects, the midlatitude route differs from the high-latitude route.

We first explain why the potential temperature decreases with descent. Figure 14 shows the potential temperature and parcel positions on backward trajectories at 18:00 UTC, 

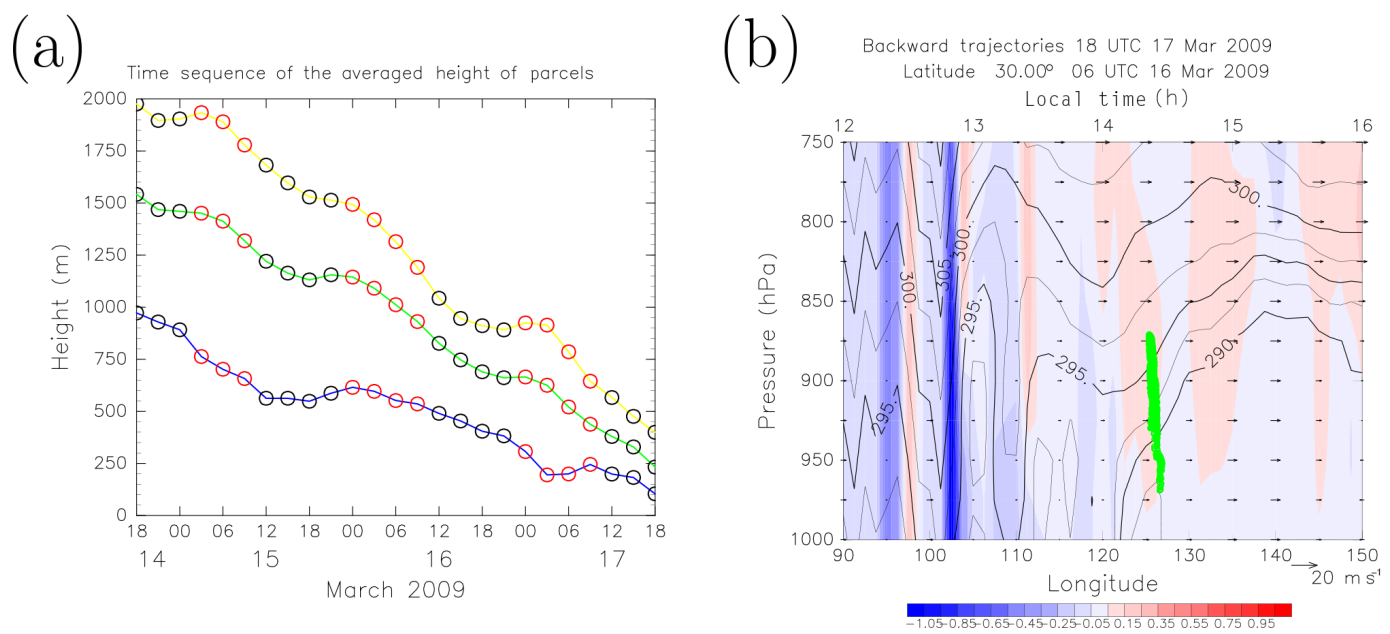

Figure 11. (a) Time change of the average heights of all the air parcels (green line), lowest-10\% parcels (blue line) and highest-10\% parcels (yellow line) on the trajectories for case 1 . The ordinate is height, and the abscissa is time. The red and black circles indicate the average heights at daytime (08:00-20:00 LT) and nighttime (20:00-08:00 LT), respectively. (b) Same as Fig. 10 but for a small area along 30 $\mathrm{N}$ at 06:00 UTC, 16 March 2009. In addition, the local time (h) is indicated in the upper axis.
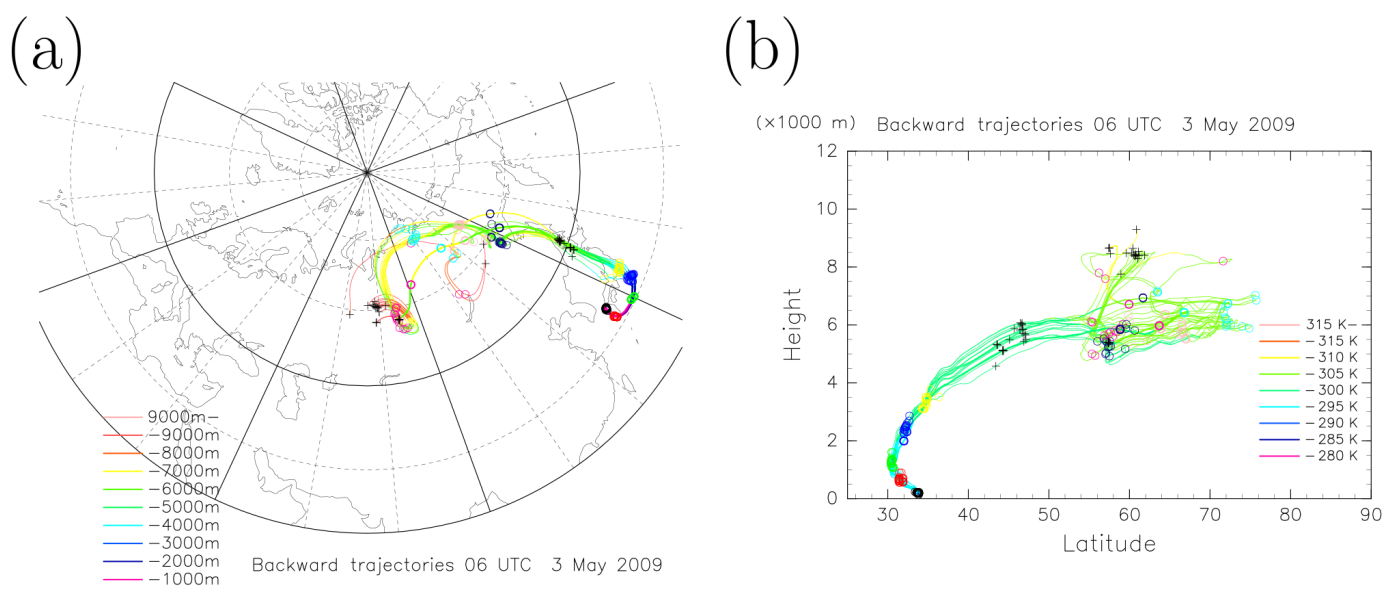

Figure 12. Same as Fig. 6 but for case 3 (starting time of 06:00 UTC, 3 May 2009).

16 December. The time is just before the marked descent. The potential temperatures of air parcels have various values, which ultimately mix $^{3}$. Because the number of parcels with high potential temperature at high altitudes is relatively small, the potential temperature is not conserved and decreases. The fact that the top- $1 \%$ averaged route differs from the top- $25 \%$ is a manifestation of this mixing.

However, the reason for such mixing is still poorly understood. Then, the relationship between the parcel positions on trajectories and the horizontal pattern on an isentropic surface is shown in Fig. 15. The area near air parcels at high altitudes (the area near $40-45^{\circ} \mathrm{N}$ and $60-75^{\circ} \mathrm{E}$ ) corresponds

\footnotetext{
${ }^{3}$ Strictly speaking, parcels themselves do not mix; instead, they approach each other. However, the distances among them are less than the grid length; thus, we express this state as "mixed". Similar expressions are used below.
}

to a diffluent-wind area associated with a blocking high (area of low height nearly coincides with the blocking high; not shown), and the northward and southward flows with descent are split. The parcels on the trajectories ride on the southward flow of these two flows. That is, descending parcels are not most of the parcels coming from the west but parts of them, because the other parts ride on the northward flow. Moreover, Fig. 16 shows that descending parcels push isentropic surfaces (moving direction of air parcels and isentropic surfaces are not parallel). Therefore, many parcels do not descend as a whole; rather, only parts of them descend as the isentropic surfaces are pushed. For such descent, descending parcels are easily mixed with parcels having low potential temperature, which originally exist in lower layers in which descending parcels arrive. 
(a)

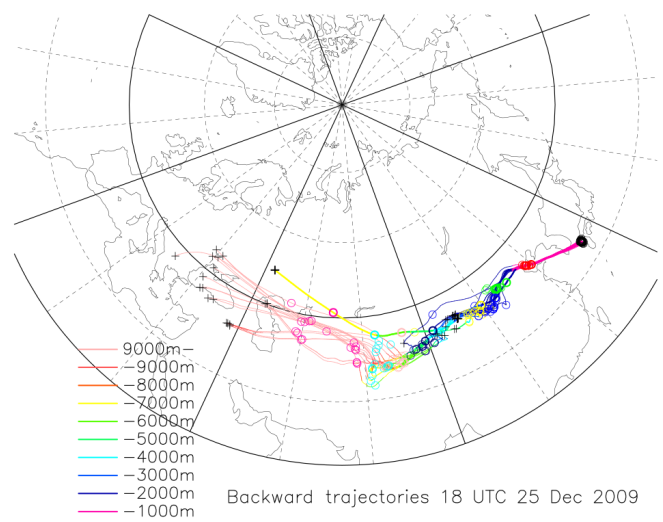

(b)

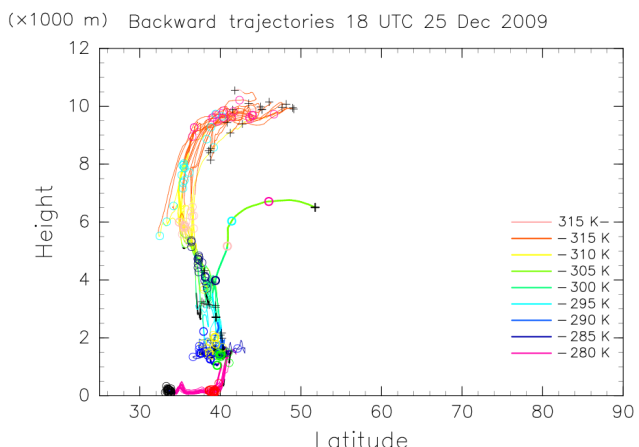

Figure 13. Same as Fig. 6 except for case 7 (starting time of 18:00 UTC, 25 December 2009).

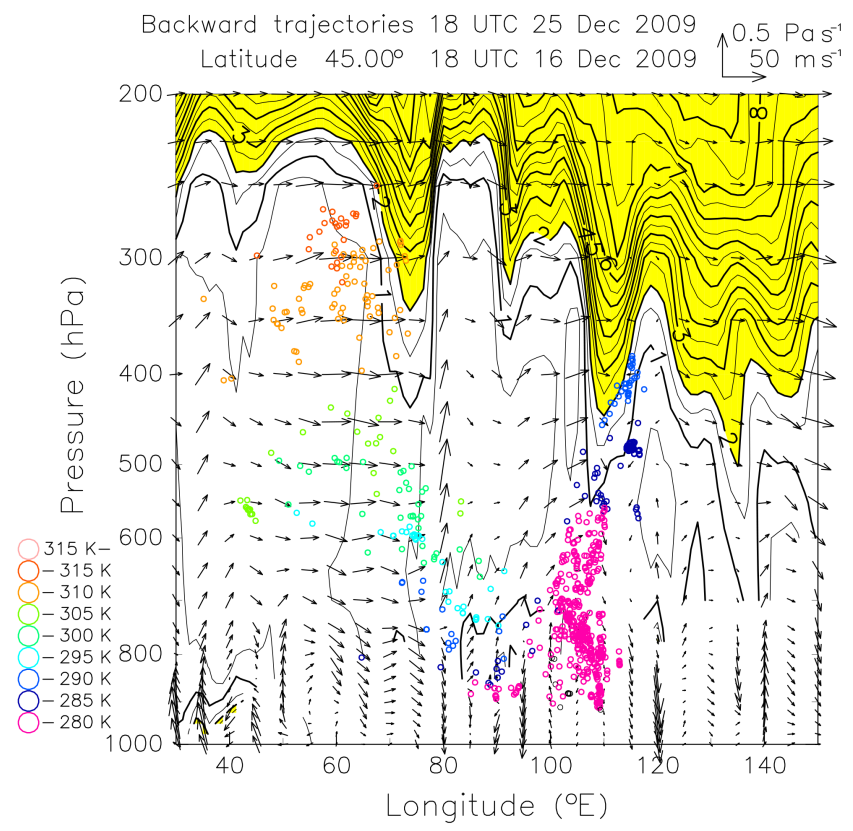

Figure 14. $\mathrm{PV}$ and parcel positions on backward trajectories in the longitude-vertical section along $45^{\circ} \mathrm{N}$ at 18:00 UTC, 16 December 2009. Parcels within $500 \mathrm{~km}$ from $45^{\circ} \mathrm{N}$ are plotted with the potential temperature represented by color.

Compared with these characteristics, we reconsider the reason for the conservation of the potential temperature in the high-latitude route. The flow in the high-latitude route is along an isentropic surface. Therefore, all parcels head southward; that is, they face the same direction. This characteristic allows the potential temperature to be conserved in the highlatitude route.

Other than case 7, all top- $1 \%$ trajectories of cases 5 and 26 show the midlatitude route. In these parcels on the trajecto-

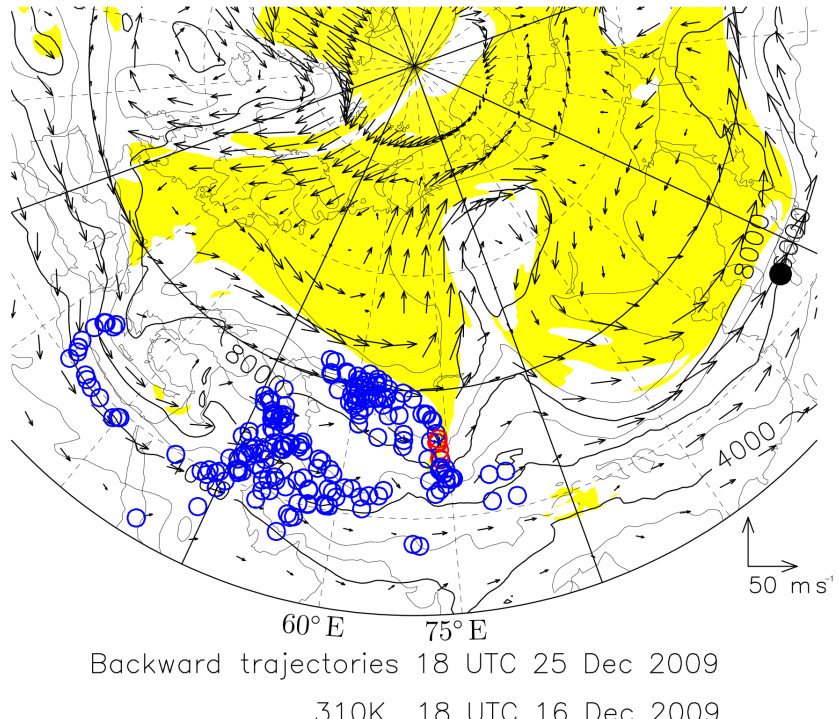

Figure 15. Same as Fig. 7a except for the $310 \mathrm{~K}$ isentropic surface at 18:00 UTC, 16 December 2009.

ries as well, only a part of the flows descend from a diffluentwind field, pushing isentropic surfaces, although the characteristic of a blocking-high accompaniment is not seen.

\subsubsection{Other characteristic routes}

Figure 17 shows the top- $1 \%$ backward trajectories of case 19 (starting time of 12:00 UTC, 16 May 2011), which is an example showing the rapid descent illustrated in Fig. 3. As the highest altitude reached in the average route is attained near $50^{\circ} \mathrm{N}$ (Fig. 17b), this case is not classified as a highlatitude route even though the parcels actually originate from high latitudes. However, unlike general cases of the highlatitude route, the trajectories do not show slow descent with 


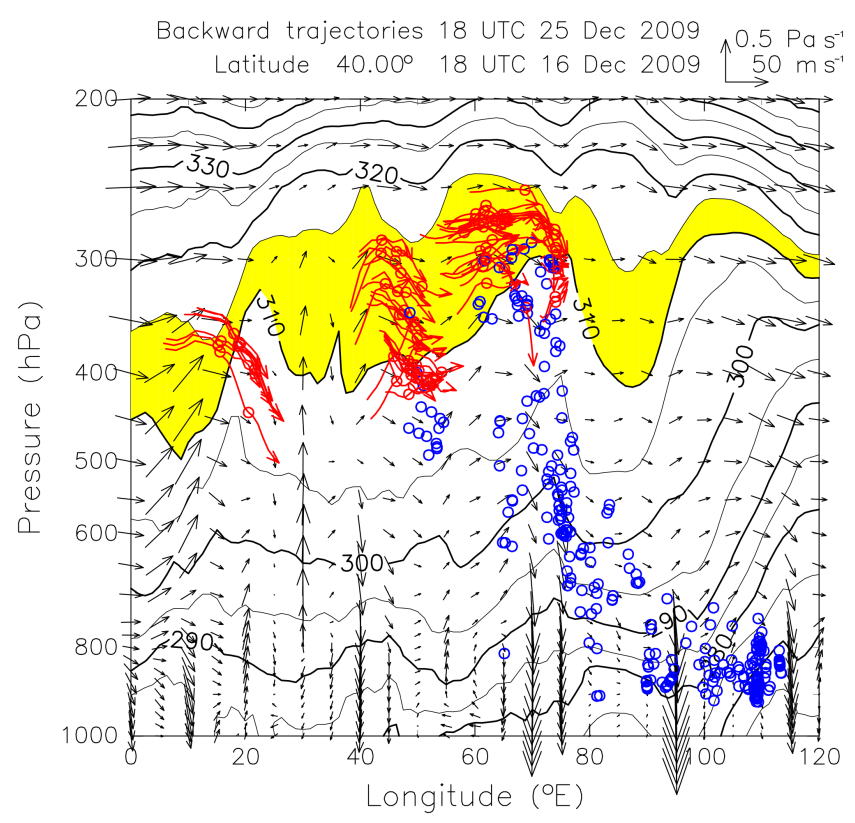

Figure 16. Potential temperature and parcel positions on backward trajectories in the longitude-vertical section along $40^{\circ} \mathrm{N}$ at 18:00 UTC, 16 December 2009. Parcels with red (blue) show potential temperature values of more (less) than $310 \mathrm{~K}$. Movement between $6 \mathrm{~h}$ before and after the present time for red parcels is indicated by arrows.

southward movement; instead, they move to about $50^{\circ} \mathrm{N}$ while maintaining almost constant altitude. This occurs because this movement is associated with the extension of the polar vortex southward to the Altai-Sayan region (around $90^{\circ} \mathrm{E}$ and $50^{\circ} \mathrm{N}$ ) rather than with the flow at the rear side of a trough (not shown). Because this process is also the cutoff of strong PV near the polar region, it can be grasped as the southward movement of tropopause folding (not shown; see also Fig. 18b). After that, the parcels descend rapidly. Because this descent from high altitudes to low altitudes occurs within the midlatitudes, the potential temperature is not conserved along the trajectories (Fig. 17b), as in case 7.

The most interesting point in this case is its fast speed of descent of $4659 \mathrm{~m}$ per 1 day and $6892 \mathrm{~m}$ per 2 days. Figure 18 shows the horizontal pattern and parcel positions of the trajectories just prior to the large descent. The parcels showing large descent are located near $50^{\circ} \mathrm{N}$ and $105^{\circ} \mathrm{E}$. Figure 18a shows that the parcels are located south of a diffluentwind field. Furthermore, the potential temperature is high at both its south and east sides; thus, the gradient of the potential temperature is large in both directions. Considering this situation in terms of the isentropic surface, the height decreases dramatically in the direction of parcel movement. In fact, as confirmed by Fig. 18b, the height decreases by more than $4000 \mathrm{~m}$ at the southeast side, where the parcels actually move. Moreover, the parcels exist in a diffluent-wind field, and their downward motion pushes isentropic surfaces.
Consequently, parcels with high potential temperature at high altitudes mix with parcels having low potential temperature at lower altitudes, leading to a decrease in the high potential temperature. By repeating this process, parcels that are originally at high altitudes descend to low altitudes. These facts and considerations indicate that parcels exist in the strongsubsidence region on an isobaric surface (Fig. 18a) and experience rapid descent.

\section{Discussion}

\subsection{Reason that the high-latitude route is the major route}

In the previous section, it is shown that the descent route from high latitudes is dominant among all descent routes. Here, its necessity is elucidated.

First, we conclude from our analysis that it is rare for parcels to be transported within midlatitudes from high to low altitudes while maintaining high concentrations of ${ }^{7} \mathrm{Be}$ included in high-altitude parcels (Kownacka, 2002; Land and Feichter, 2003): in this route, as mentioned in Sect. 4.2.2, parcels at high altitudes necessarily mix with those at low altitudes. This means that ${ }^{7} \mathrm{Be}$ concentrations inevitably decrease; therefore, the midlatitude route is not a typical one, as observational events of high concentrations of ${ }^{7} \mathrm{Be}$ indicate. Therefore, for parcels to arrive at the near-surface level (about 2000-3000 m) at midlatitudes while conserving their potential temperature, i.e., maintaining high concentrations of ${ }^{7} \mathrm{Be}$, their starting area should be high latitudes, where the potential temperature is nearly the same as that in the arrival area. Moreover, owing to the long-distance transport from high latitudes to midlatitudes, large-scale disturbances are always included. Thus, parcels always ride on the northerly wind associated with developed troughs.

In the high-latitude route, the altitudes of the parcels are generally lowered by tropopause folding, and the parcels are then transported to midlatitudes. This process is also inevitable and is explained below.

Figure 19 shows the meridional inclination of each potential temperature with reference to the monthly mean potential temperature at 8000 and $10000 \mathrm{~m}$ at $70^{\circ} \mathrm{N}$. The inclination of the potential temperature in each month is not markedly different with reference to the $8000 \mathrm{~m}$ potential temperature, although the potential temperature itself is different. That is, no particular month is easier than the other for effective parcel descent from high to low altitudes during the movement from high to midlatitudes. In contrast, a significant difference is noted between the inclinations of the two reference altitudes of 8000 and $10000 \mathrm{~m}$. That is, isentropic surfaces for the $8000 \mathrm{~m}$ reference have large inclinations, whereas those for the $10000 \mathrm{~m}$ reference have small inclinations.

On the basis of these results, the following conclusions are drawn. First, when parcels are transported from high to 


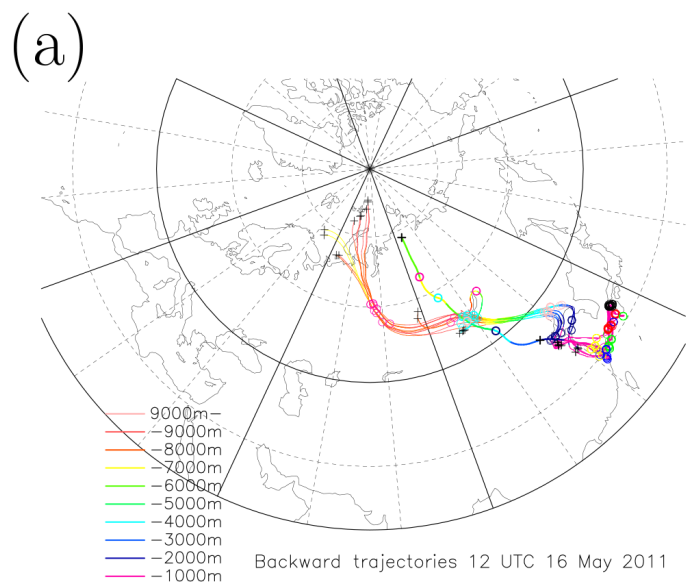

(b)

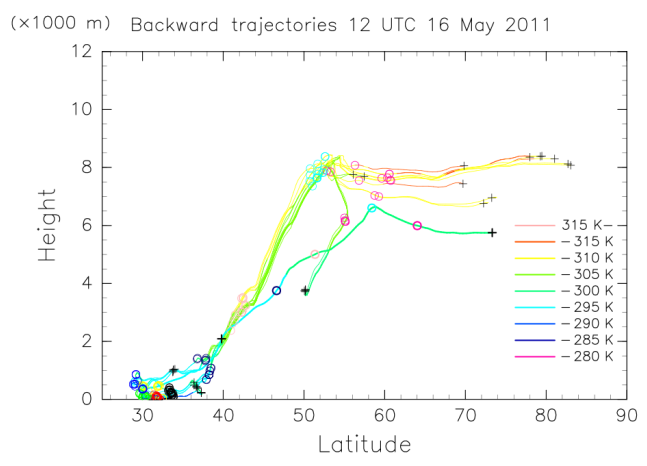

Figure 17. Same as Fig. 6 except for case 19 (starting time of 12:00 UTC, 16 May 2011).
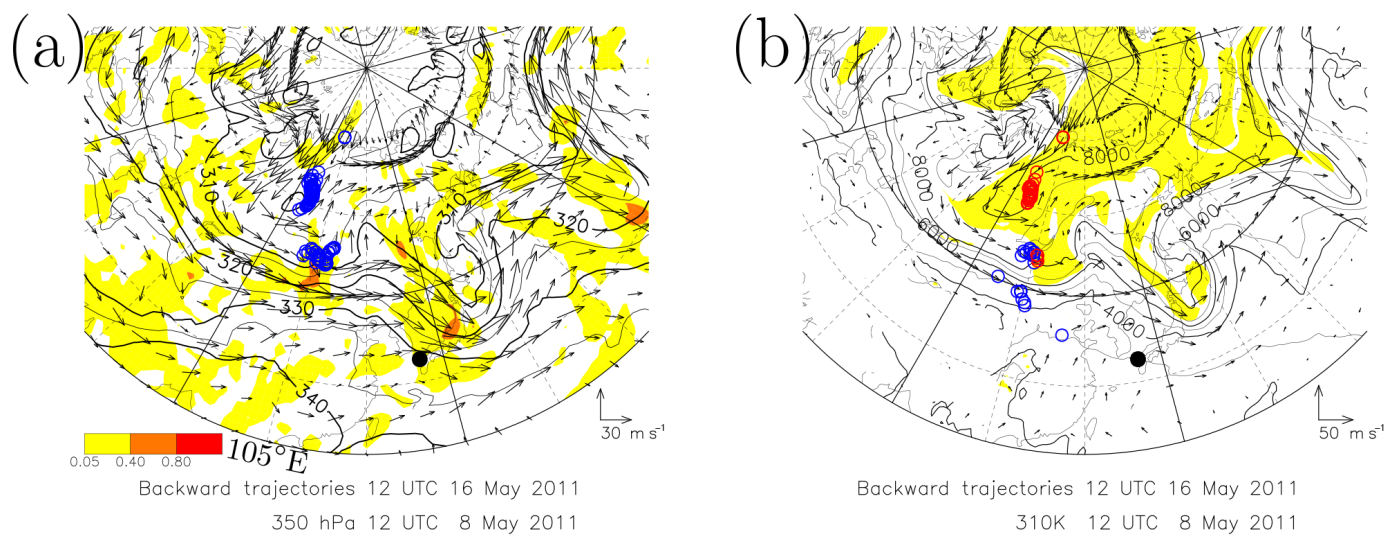

Figure 18. (a) Potential temperature (contour; unit: K), downward flow (shading; unit: $\mathrm{Pa} \mathrm{s}^{-1}$ ), and wind (arrows) on the $350 \mathrm{hPa}$ level and (b) height (contour; unit: $\mathrm{m}$ ) and wind (arrows) on the $300 \mathrm{~K}$ isentropic surface at 12:00 UTC, 8 May 2011. Yellow indicates areas of more than 2 PVU in panel (b). The parcel positions are shown within height differences of $1000 \mathrm{~m}$.

midlatitudes at altitudes of more than $10000 \mathrm{~m}$, the height changes little. In contrast, when the starting altitudes are near $8000 \mathrm{~m}$, the parcel height decreases dramatically during the movement to midlatitudes. Thus, for parcels in the stratosphere to effectively reach low altitudes at midlatitudes, the parcel height must diminish to less than $10000 \mathrm{~m}$. Furthermore, a larger decrease is related to more effective access to the surface. For this reason, a potential path for parcel descent is with tropopause folding at the initial stage.

\subsection{Reason for frequent high-concentration days in spring}

In this subsection, we clarify the reason for the large number of high-concentration days of ${ }^{7} \mathrm{Be}$ at Fukuoka in spring. Three possibilities are given considering the descent route: the frequency of tropopause folding at high latitudes, disturbances that transport parcels southward from high latitudes, and near-surface disturbances in the transport of parcels to the surface are different between spring and other sea- sons. Of course, high-concentration days of ${ }^{7} \mathrm{Be}$ appear easily when frequencies of tropopause folding are high, disturbances transporting the parcels southward are strong, and parcels are effectively transported to the surface by nearsurface disturbances. The difference in the meridional inclination of isentropic surfaces in the troposphere is one possibility. However, as shown in the previous subsection, this difference is small enough to be excluded from the possibilities. Then, these three are examined. The data used for these analyses are the $1.25^{\circ}$-grid isentropic analysis data for frequencies of tropopause folding and disturbances transporting parcels southward in addition to the model-grid data for near-surface disturbances.

The climatological tropopause folding was examined by Sprenger et al. (2003) (see also Añel et al., 2008). However, their definition seems to cover exclusively folding with bending, but it does not cover folding that hangs down straightly. Therefore, we make our own definition, examining tropopause folding. The definition is the state at which 


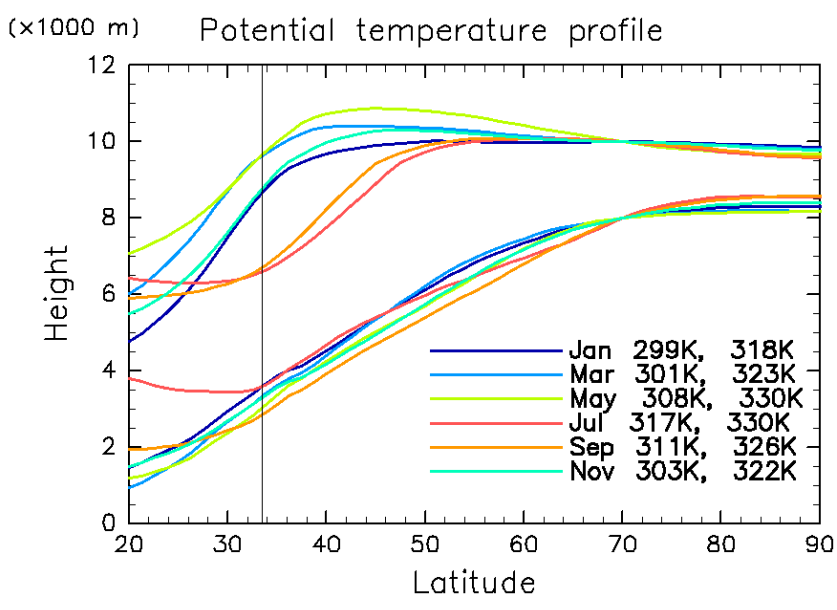

Figure 19. Meridional inclination of each potential temperature with reference to the monthly mean potential temperature at 8000 and $10000 \mathrm{~m}$ heights at $70^{\circ} \mathrm{N}$. The potential temperature is shown at the right side of each month (left: $8000 \mathrm{~m}$; right: $10000 \mathrm{~m}$ ). The averages between $30^{\circ} \mathrm{W}$ and $120^{\circ} \mathrm{E}$ are shown for only the odd months.

the PV surface of 3 PVU trails down to less than $6000 \mathrm{~m}$, although this definition may be a bit exclusive, and it may apply to cases with no precise tropopause folding. Figure 20 shows the seasonal difference in the frequencies of tropopause folding at $30^{\circ} \mathrm{W}-120^{\circ} \mathrm{E}$, hereafter referred to as the Eurasian region. This region nearly corresponds to the starting region of the parcels, as shown in Fig. 3a. Figure 20 shows that the tropopause folds are frequent at high latitudes in spring and at $40-50^{\circ} \mathrm{N}$ in winter. The frequencies are generally slightly higher in spring than in winter. For our purposes, however, we consider that these two seasons show no significant differences. Low frequencies in summer and autumn can explain the lower number of high-concentration days in these two seasons. Needless to say, a more detailed analysis of tropopause folding in high latitudes is necessary, because its definition adopted in this study is rough.

Next, disturbances transporting parcels southward are examined. Because parcels are transported by the northerly wind at the rear side of troughs, the strength of the northerly is examined such that the 2-8-day period component of the meridional wind is extracted, and its variance is compared. The variances in winter and spring among the four seasons are shown in Fig. 21. Although the variance is larger in winter than in spring in the Pacific and Atlantic regions, it is larger in spring than in winter in the Eurasian region in question. In winter, we consider that disturbances in that region are weak because the connection is weak from the storm track region in the Atlantic to the polar frontal jet in the Eurasian region, and disturbances in the Atlantic are connected to the strongwind region in the Mediterranean. In contrast, in spring, owing to the weak wind in the Mediterranean, the polar frontal jet is connected to the storm track region in the Atlantic;

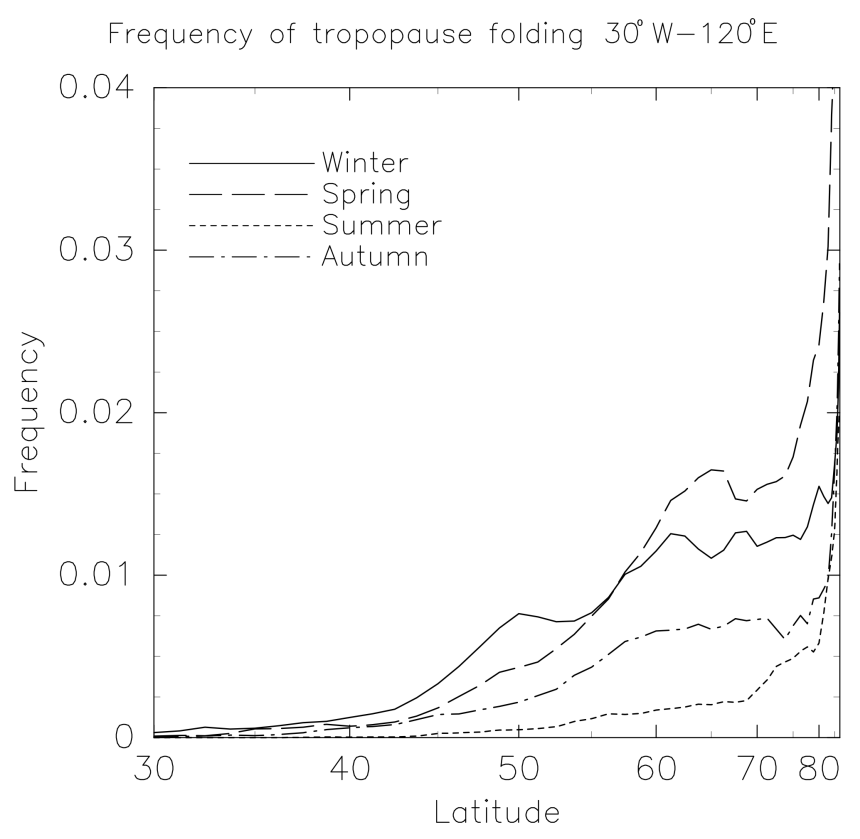

Figure 20. Seasonal frequencies of tropopause folding. The abscissa is the latitude elongated and contracted by the area factor. The frequencies are averaged between $30^{\circ} \mathrm{W}$ and $120^{\circ} \mathrm{E}$.

thus, the disturbances are considered to be strong in the polar frontal jet. For the other seasons, the variance in autumn shows almost the same feature as that in spring, and the variance in summer is very small (not shown).

Finally, the differences in near-surface disturbances are investigated. The working hypothesis is that near-surface disturbances and their associated wind systems show marked characteristics between seasons, and some wind systems match and other systems mismatch parcels coming to Fukuoka by subsidence from low altitudes at midlatitudes. For example, in winter, parcels are usually transported to Japan from the north within low altitudes owing to the dominance of the northerly winter monsoon, resulting in a mismatch of the wind system with the descent routes clarified thus far. Then, we examined the differences in backward trajectories between January 2011, when no high-concentration events occurred, and April of the same year. Backward trajectories were calculated for 31 and 30 times starting from 00:00 UTC on all days in January and April, respectively.

Figure 22 shows the results. The backward trajectories drastically differ between January and April: all trajectories in January move northward, advancing to higher latitudes while maintaining relatively low altitudes, whereas those in April show both northward and southward movements with many ascending to relatively high altitudes. Of course, eastward and westward movements also exist (not shown). This characteristic of movements in various directions in April is consistent with that shown in Fig. 5. These features in January and April are confirmed to be similar in other years. 

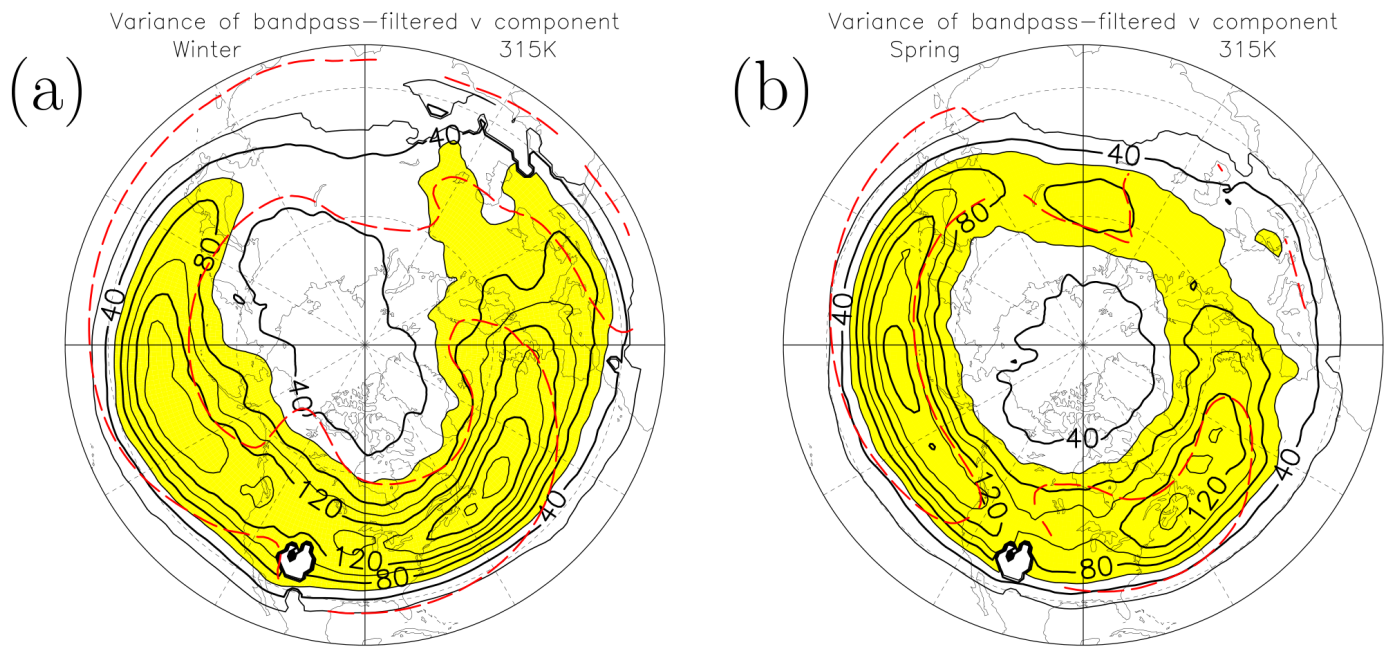

Figure 21. Variances of the bandpass-filtered meridional-wind component (unit: $\mathrm{m}^{2} \mathrm{~s}^{-2}$ ) at the $315 \mathrm{~K}$ isentropic surface in winter (left) and spring (right). Areas with more than $60 \mathrm{~m}^{2} \mathrm{~s}^{-2}$ are shown in yellow. Red dashed lines indicate the climatological zonal-wind component of $15 \mathrm{~m} \mathrm{~s}^{-1}$. These values are calculated between 2009 and 2014. Values are missing in some regions of low latitudes owing to a lack of data for low potential temperature.

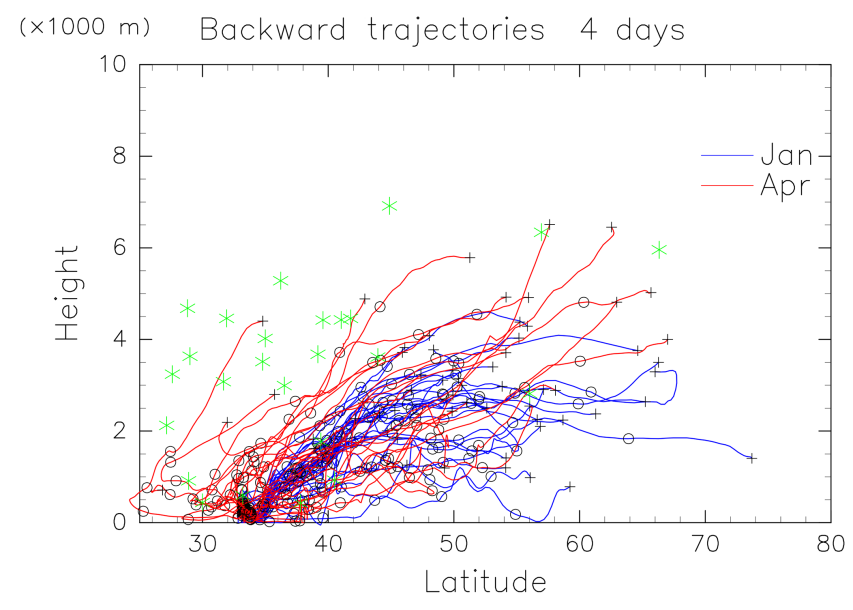

Figure 22. Projections of backward trajectories to the latitudevertical section for 4 days from 00:00 UTC on all days in January and April in 2010. The $\circ$ and + symbols indicate positions at 00:00 UTC. The green star marks represent the parcels on 4 days before the starting time on the trajectories that show the highest altitude for all 33 cases.

Similar calculations were conducted in July and October. The trajectories in October are similar to those in April. In July, many trajectories move southward, although some move in other directions. In addition, many trajectories remain within very low altitudes of less than $2000 \mathrm{~m}$ for 4 days.

From the above, the reason for the frequent highconcentration days in spring is clear: in spring, tropopause folds are frequent at high latitudes, disturbances transporting parcels southward are strong, and near-surface disturbances lowering parcels to the surface are ubiquitous. On the other hand, some of these conditions are unfavorable in the other three seasons. In winter, although tropopause folds are frequent, the wind transporting parcels southward is not as strong and, in particular, near-surface disturbances transporting them to the surface do not exist in general. In autumn, although the last two conditions are favorable, tropopause folds are not frequent. In summer, all three conditions are unfavorable. As a result, high-concentration events of ${ }^{7} \mathrm{Be}$ are virtually absent.

\section{Conclusions and future perspective}

By using high concentrations of ${ }^{7} \mathrm{Be}$ as an indicator, fast descent routes from within or near the stratosphere to Earth's surface, with the study site being in Fukuoka, Japan, were elucidated. Here, "fast" means "within 10 days".

The majority of descent routes are from high latitudes and follow a particular sequence, as shown in Fig. 23: first, a descent associated with tropopause folding occurs, followed by southward movement with slow descent by the northerly wind at the rear side of a strong trough. Because this motion is along isentropic surfaces, air parcels descend while nearly conserving their potential temperature. In this extension, a strong descent associated with a sharp drop in isentropicsurface height occurs at the southern edge of the trough. This process involves irreversible phenomena such as filamentation and cutoff of potential vorticity. Therefore, descending parcels migrate at low altitudes without the turnaround along the southern edge of a trough and subsequent northward movement with slow ascent. Finally, by meeting nearsurface disturbances to transport parcels from low altitudes to Earth's surface, the parcels are transported to the surface. 


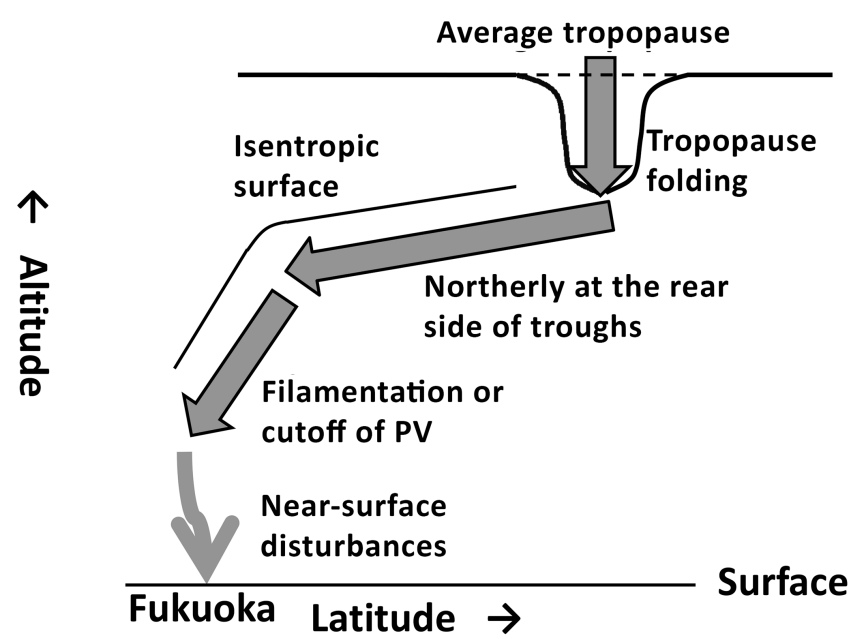

Figure 23. Schematic diagram of the descent from high latitudes.

These disturbances have no specific form but various forms. The daily variation of the atmospheric boundary layer (ABL) is important for the air parcels on the trajectories intruding into the ABL. That is, the air parcels above the ABL are easily taken into the ABL due to the development of the mixed layer during daytime, while it is difficult for them to enter the ABL during nighttime.

In some cases, parcels descend directly from high altitudes within midlatitudes. In such cases, the potential temperature is not conserved; instead, it decreases. This result occurs because the potential temperature is high in these regions, and large descent never occurs while conserving the potential temperature. Thus, a decrease in potential temperature is inevitable for large descents. For this to occur, a diffluentwind field on isentropic surfaces is necessary, where some part of the flow moves northward and the other part moves southward with descent. When these descending parcels push low isentropic surfaces, their potential temperature decreases upon mixing with parcels having lower potential temperature at lower altitudes. Then, by the repetition of this process, the height of the parcels decreases drastically. The route from low altitudes to the surface is the same as in the high-latitude route as mentioned above.

We clarified the necessity that the high-latitude route is dominant. In the midlatitude route, the mixing between parcels at high and relatively low altitudes is inevitable; that is, the high concentrations of ${ }^{7} \mathrm{Be}$ in high-altitude parcels are difficult to maintain. Therefore, for parcels to arrive at low altitudes in the midlatitudes while maintaining high concentrations of ${ }^{7} \mathrm{Be}$, i.e., conserving the potential temperature, their starting area should be high altitudes at high latitudes, where the potential temperature is nearly the same as that in the arrival area. In addition, we revealed the reason for the mandatory initial descent; when parcels in the stratosphere start to move to midlatitudes, descent never occurs. In contrast, for descent to be effective, it is necessary that parcels must al- ready be lowered from the stratosphere to the troposphere at high latitudes before moving to midlatitudes.

Many high-concentration events of ${ }^{7} \mathrm{Be}$ occur in spring because, in this season, tropopause folds are frequent at high latitudes, disturbances transporting parcels southward are strong, and near-surface disturbances lowering them to the surface are ubiquitous. On the other hand, because some of these conditions are unfavorable in the other three seasons, high-concentration events of ${ }^{7} \mathrm{Be}$ are not frequent. In particular, they are virtually absent in summer.

Finally, we present a view of future work following the present study. This study examined fast descent routes to a specific location, i.e., Fukuoka, Japan. However, by extending the present results, we can examine fast descent routes to other locations; we believe that the majority of them are from regions in which tropopause folds are frequent. As confirmed in relation to Fig. 20, such regions include the northeastern part of the Asian continent and the northern and northeastern parts of North America in spring, in addition to the northern part of North America and storm track regions in the Pacific and Atlantic in winter (not shown). Then, if forward trajectories are traced from these regions with starting times at which tropopause folding occurs, some trajectories may arrive at the surface. From these calculations, many fast descent routes will be revealed.

Furthermore, it is interesting to consider the material and chemical differences in the air in regions of fast descent routes from those of general tropospheric air. We can easily predict elevated ozone concentrations and low specific humidity; however, other characteristics are possible. Therefore, several new research topics such as chemical reactions in the air will be discussed in the future.

\section{The Supplement related to this article is available online at doi:10.5194/acp-16-6241-2016-supplement.}

Acknowledgements. We would like to thank S. Miyahara for many useful comments in the development of this work. Thanks are extended to the three anonymous reviewers and the editor (P. Haynes) for many valuable and constructive comments. In particular, one reviewer recommended an analysis of the difference in the behavior of the air parcels on the trajectories between daytime and nighttime in the atmospheric boundary layer. These comments led to substantial improvements of the paper. The GFD-DENNOU Libraries and GrADS were used for producing the figures.

Edited by: P. Haynes 


\section{References}

Ambrose, J. L., Reidmiller, D. R., and Jaffe, D. A.: Causes of high $\mathrm{O}_{3}$ in the lower free troposphere over the Pacific Northwest as observed at the Mt. Bachelor Observatory, Atmos. Environ. 45, 5302-5315, 2011.

Añel, J. A., Antuña, J. C., de la Torre, L., Castanheira, J. M., and Gimeno, L.: Climatological features of global multiple tropopause events, J. Geophys. Res., 113, D00B08, doi:10.1029/2007JD009697, 2008.

Bezuglov, M. V., Malyshevsky, V. S., Fomin, G. V., Torgovkin, A. V., Shramenko, B. I., and Malykhina, T. V.: Photonuclear production of cosmogenic beryllium-7 in the terrestrial atmosphere, Phys. Rev. C, 86, 024609, doi:10.1103/PhysRevC.86.024609, 2012.

Bracci, A., Cristofanelli, P., Sprenger, M., Bonafe, U., Calzolari, F., Duchi, R., Laj, P., Marinoni, A., Roccato, F., E. Vuillermoz, E., and Bonasoni, P.: Transport of stratospheric air masses to the Nepal Climate Observatory-Pyramid (Himalaya; $5079 \mathrm{~m}$ MSL): A synoptic-scale investigation, J. Appl. Meteorol. Clim., 51, 1489-1507, 2012.

Buraeva, E. A., Davydov, M. G., Zorina, L. V., Malyshevskii, V. S., and Stasov, V. V.: Content of cosmogenic ${ }^{7} \mathrm{Be}$ in the air layer at the ground at temperate latitudes, Atom Energy+, 102, 463-468, 2007

Chen, X., Añel, J. A., Su, Z., de la Torre, L., Kelder, H., van Peet, J., and Ma, Y.: The deep atmospheric boundary layer and its significance to the stratosphere and troposphere exchange over the Tibetan Plateau, PLoS ONE, 8, e56 909, doi:10.1371/journal.pone.0056909, 2013.

Chen, X., Škerlak, B., Rotach, M. W., Añel, J. A., Su, Z., Ma, Y., and Li, M.: Reasons for the extremely high-ranging planetary boundary layer over the western Tibetan Plateau in winter, J. Atmos. Sci., 2021-2038, doi:10.1175/JAS-D-15-0148.1, 2016.

Chen, X. L., Ma, Y. M., Kelder, H., Su, Z., and Yang, K.: On the behaviour of the tropopause folding events over the Tibetan Plateau, Atmos. Chem. Phys., 11, 5113-5122, doi:10.5194/acp11-5113-2011, 2011.

Cristofanelli, P., Bonasoni, P., Collins, W., Feichter, J., Forster, C., James, P., Kentarchos, A., Kubik, P. W., Land, C., Meloen, J., Roelofs, G. J., Siegmund, P., Sprenger, M., Schnabel, C., Stohl, A., Tobler, L., Tositti, L., Trickl, T., and Zanis, P.: Stratosphereto-troposphere transport: a model and method evaluation, J. Geophys. Res., 108, 8525, doi:10.1029/2002JD002600, 2003.

Cristofanelli, P., Bonasoni, P., Tositti, L., Bonafé, U., Calzolari, F., Evangelisti, F., Sandrini, S., and Stohl, A.: A 6-year analysis of stratospheric intrusions and their influence on ozone at Mt. Cimone (2165 m above sea level), J. Geophys. Res., 111, D03306, doi:10.1029/2005JD006553, 2006.

Cristofanelli, P., Bracci, A., Sprenger, M., Marinoni, A., Bonafè, U., Calzolari, F., Duchi, R., Laj, P., Pichon, J. M., Roccato, F., Venzac, H., Vuillermoz, E., and Bonasoni, P.: Tropospheric ozone variations at the Nepal Climate ObservatoryPyramid (Himalayas, $5079 \mathrm{~m}$ a.s.1.) and influence of deep stratospheric intrusion events, Atmos. Chem. Phys., 10, 6537-6549, doi:10.5194/acp-10-6537-2010, 2010.

Elbern, H., Kowol, J., Sladkovic, R., and Ebel, A.: Deep stratospheric intrusions: a statistical assessment with model guided analysis, Atmos. Environ., 31, 3207-3226, 1997.
Feely, H. W., Larsen, R. J., and Sanderson, C. G.: Factors that cause seasonal variations in beryllium-7 concentrations in surface air, $\mathrm{J}$. Environ. Radioactiv., 9, 223-249, 1989.

Gerasopoulos, E., Zanis, P., Stohl, A., Zerefos, C. S., Papastefanou, C., Ringer, W., Tobler, L., Hübener, S., Gäggeler, H. W., Kanter, H. J., Tositti, L., and Sandrini, S.: A climatology of ${ }^{7} \mathrm{Be}$ at four high-altitude stations at the Alps and the Northern Apennines, Atmos. Environ., 35, 6347-6360, 2001.

Holton, J. R., Haynes, P. H., McIntyre, M. E., Douglass, A. R., Rood, R. B., and Pfister, L.: Stratosphere-troposphere exchange, Rev. Geophys., 33, 403-440, 1995.

Hoskins, B. J., McIntyre, M. E., and Robertson, A. W.: On the use and significance of isentropic potential vorticity maps, Q. J. Roy. Meteor. Soc., 111, 877-946, 1985.

James, P., Stohl, A., Forster, C., Eckhardt, S., Seibert, P., and Frank, A.: A 15-year climatology of stratosphere-troposphere exchange with a Lagrangian particle dispersion model: 1 . Methodology and validation, J. Geophys. Res., 108, 8519, doi:10.1029/2002JD002637, 2003a.

James, P., Stohl, A., Forster, C., Eckhardt, S., Seibert, P., and Frank, A.: A 15-year climatology of stratosphere-troposphere exchange with a Lagrangian particle dispersion model: 2. Mean climate and seasonal variability, J. Geophys. Res., 108, 8522, doi:10.1029/2002JD002639, 2003b.

Jordan, C. E., Dibb, J. E., and Finkel, R. C.: ${ }^{10} \mathrm{Be} /{ }^{7} \mathrm{Be}$ tracer of atmospheric transport and stratosphere-troposphere exchange, J. Geophys. Res., 108, 4234, doi:10.1029/2002JD002395, 2003.

Kikuchi, S., Sakurai, H., Gunji, S., and Tokanai, F.: Temporal variation of ${ }^{7} \mathrm{Be}$ concentrations in atmosphere for $8 \mathrm{y}$ from 2000 at Yamagata, Japan: solar influence on the ${ }^{7} \mathrm{Be}$ time series, J. Environ. Radioactiv., 100, 515-521, 2009.

Kobayashi, S., Ota, Y., Harada, Y., Ebita, A., Moriya, M., Onoda, H., Onogi, K., Kamahori, H., Kobayashi, C., Endo, H., Miyaoka, K., and Takahashi, K.: The JRA-55 reanalysis: General specifications and basic characteristics, J. Meteorol. Soc. Jpn., 93, 5-48, 2015.

Kownacka, L., Vertical distributions of beryllium-7 and lead-210 in the tropospheric and lower stratospheric air, NUKLEONIKA, 47, 79-82, 2002.

Land, C. and Feichter, J.: Stratosphere-troposphere exchange in a changing climate simulated with the general circulation model MAECHAM4, J. Geophys. Res., 108, 8523, doi:10.1029/2002JD002543, 2003.

Langford, A. O., Brioude, J., Cooper, O. R., Senff, C. J., Alvarez II, R. J.,Hardesty, R. M., Johnson, B. J., and Oltmans, S. J.: Stratospheric influence on surface ozone in the Los Angeles area during late spring and early summer of 2010, J. Geophys. Res., 117, D00V06, doi:10.1029/2011JD016766, 2012.

Langford, A. O., Senff, C. J., Alvarez, R. J., Brioude, J., Cooper, O. R., Holloway, J. S., Lin, M. Y., Marchbanks, R. D., Pierce, R. B., Sandberg, S. P., Weickmann, A. M., and Williams, E. J.: An overview of the 2013 Las Vegas Ozone Study (LVOS): impact of stratospheric intrusions and long-range transport on surface air quality, Atmos. Environ., 109, 305-322, doi:10.1016/j.atmosenv.2014.08.040, 2015.

Lefohn, A. S., Wernli, H., Shadwick, D., Oltmans, S. J., and Shapiro, M.: Quantifying the importance of stratospherictropospheric transport on surface ozone concentrations at high- 
and low-elevation monitoring sites in the United States, Atmos. Environ., 62, 646-656, 2012.

Lin, M., Fiore, A. M., Cooper, O. R., Horowitz, L. W., Langford, A. O., Levy, H., Johnson, B. J., Naik, V., Oltmans, S. J., and Senff, C. J.: Springtime high surface ozone events over the western United States: quantifying the role of stratospheric intrusions, J. Geophys. Res., 117, D00V22, doi:10.1029/2012JD018151, 2012.

Lin, M., Fiore, A. M., Horowitz, L. W., Langford, A. O., Oltmans, S. J., Tarasick, D., and Rieder, H. E.: Climate variability modulates western US ozone air quality in spring via deep stratospheric intrusions, Nature Commun., 6, 7105, doi:10.1038/ncomms8105, 2015.

Ma, J., Lin, W. L., Zheng, X. D., Xu, X. B., Li, Z., and Yang, L. L.: Influence of air mass downward transport on the variability of surface ozone at Xianggelila Regional Atmosphere Background Station, southwest China, Atmos. Chem. Phys., 14, 5311-5325, doi:10.5194/acp-14-5311-2014, 2014.

Machta, L.: Discussion of meteorological factors and fallout distribution, U.S. Weather Bureau, 11 pp., 1957.

Masarik, J., and Beer, J.: Simulation of particle fluxes and cosmogenic nuclide production in the Earth's atmosphere, J. Geophys. Res., 104, 12099-12111, 1999.

Megumi, K., Matsunami, T., Ito, N., Kiyoda, S., Mizohata, A., and Asano, T.: Factors, especially sunspot number, causing variations in surface air concentrations and depositions of ${ }^{7} \mathrm{Be}$ in Osaka, Japan, Geophys. Res. Lett., 27, 361-364, 2000.

Nagai, H., Tada, W., and Kobayashi, T.: Production rates of ${ }^{7} \mathrm{Be}$ and ${ }^{10} \mathrm{Be}$ in the atmosphere, Nucl. Instrum. Methods, 172, 796-801, 2000.

Narazaki, Y. and Fujitaka, K.: Cosmogenic ${ }^{7}$ Be: atmospheric concentration and deposition in Japan, Japanese J. Health Phy., 44, 95-105, 2009.

Nieto, R., Sprenger, M., Wernli, H., Trigo, R. M., and Gimeno, L.: Identification and climatology of cut-off lows near the tropopause, Trend. Direct. Climate Res., Ann. NY Acad. Sci., 1146, 256-290, 2008.

Ojha, N., Najaa, M., Sarangi, T., Kumar, R., Bhardwaj P, Lal, S., Venkataramani, S., Sagar, R., Kumar, A., Chandola, H. C.: On the processes influencing the vertical distribution of ozone over the central Himalayas: Analysis of yearlong ozonesonde observations, Atmos. Environ., 88, 201-211, 2014.

Oltmans, S. J. and Levy II., H.: Seasonal cycle of surface ozone over the western North Atlantic, Nature, 358, 392-394, 1992.

Raisbeck, G. M., Yiou, F., Fruneau, M., Loiseaux, J. M., Lieuvin, M., and Ravel, J. C.: Cosmogenic ${ }^{10} \mathrm{Be} /{ }^{7} \mathrm{Be}$ as a probe of atmospheric transport processes, Geophys. Res. Lett., 8, 10151018, 1981.

Reed, R. J. and Sanders, F.: An investigation of the development of a mid-tropospheric frontal zone and its associated vorticity field, J. Meteorol., 10, 338-349, 1953.

Škerlak, B., Sprenger, M., and Wernli, H.: A global climatology of stratosphere-troposphere exchange using the ERA-Interim data set from 1979 to 2011, Atmos. Chem. Phys., 14, 913-937, doi:10.5194/acp-14-913-2014, 2014.

Sprenger, M. and Wernli, H.: A Northern Hemisphere climatology of cross-tropopause exchange for the ERA15 time period (1979-1993), J. Geophys. Res., 108, D128521, doi:10.1029/2002JD002636, 2003.
Sprenger, M., Croci Maspoli, M., and Wernli, H.: Tropopause folds and cross-tropopause transport: a global investigation based upon ECMWF analyses for the time period March 2000 to February 2001, J. Geophys. Res., 108, 8518, doi:10.1029/2002JD002587, 2003.

Stohl, A., Spichtinger-Rakowsky, N., Bonasoni, P., Feldmann, H., Memmesheimer, M., Scheel, H. E., Trickl, T., Hubener, S., Ringer, W., and Mandl, M.: The influence of stratospheric intrusions on Alpine ozone concentrations. Atmos. Environ., 34, 1323-1354, 2000.

Stohl, A., Bonasoni, P., Cristofanelli, P., Collins, W., Feichter, J., Frank, A., Forster, C., Gerasopoulos, E., Gäggeler, H., James, P., Kentarchos, T., Kromp-Kolb, H., Krüger, B., Land, C., Meloen, J., Papayannis, A., Priller, A., Seibert, P., Sprenger, M., Roelofs, G. J., Scheel, H. E., Schnabel, C., Siegmund, P., Tobler, L., Trickl, T., Wernli, H., Wirth, V., Zanis, P., and Zerefos, C.: Stratosphere-troposphere exchange: a review, and what we have learned from STACCATO, J. Geophys. Res., 108, 8516, doi:10.1029/2002JD002490, 2003.

Tositti, L., Brattich, E., Cinelli, G., and Baldacci, D.: 12 years of ${ }^{7} \mathrm{Be}$ and ${ }^{210} \mathrm{~Pb}$ in Mt. Cimone, and their correlation with meteorological parameters, Atmos. Environ., 87, 108-122, 2014.

Trickl, T., Feldmann, H., Kanter, H.-J., Scheel, H.-E., Sprenger, M., Stohl, A., and Wernli, H.: Forecasted deep stratospheric intrusions over Central Europe: case studies and climatologies, Atmos. Chem. Phys., 10, 499-524, doi:10.5194/acp-10-499-2010, 2010.

Trickl, T., Vogelmann, H., Giehl, H., Scheel, H.-E., Sprenger, M., and Stohl, A.: How stratospheric are deep stratospheric intrusions?, Atmos. Chem. Phys., 14, 9941-9961, doi:10.5194/acp14-9941-2014, 2014.

Tsutsumi, Y., Igarashi, Y., Zaizen, Y., and Makino, Y.: Case studies of tropospheric ozone events observed at the summit of Mount Fuji, J. Geophys. Res., 103, 16935-16951, 1998.

US Environmental Protection Agency (US EPA): Air Quality Criteria for Ozone and Related Photochemical Oxidants (2006 Final), EPA/600/R-05/004aF-cF, US Environ. Prot. Agency, Washington, D.C., USA, 821 pp., 2006.

Usoskin, I. G. and Kovaltsov, G. A.: Production of cosmogenic ${ }^{7}$ Be isotope in the atmosphere: Full 3-D modeling, J. Geophys. Res., 113, D12107, doi:10.1029/2007JD009725, 2008.

Usoskin, I. G., Field, C. V., Schmidt, G. A., Leppänen, A.-P., Aldahan, A., Kovaltsov, G. A., Possnert, G., and Ungar, R. K.: Short-term production and synoptic influences on atmospheric ${ }^{7}$ Be concentrations, J. Geophys. Res., 114, D06108, doi:10.1029/2008JD011333, 2009.

Wernli, H. and Bourqui, M.: A Lagrangian "1-year climatology" of (deep) cross-tropopause exchange in the extratropical Northern Hemisphere, J. Geophys. Res., 107, D24021, doi:10.1029/2001JD000812, 2002.

Yates, E. L., Iraci, L. T., Roby, M. C., Pierce, R. B., Johnson, M. S., Reddy, P. J., Tadic, J. M., Loewenstein, M., and Gore, W.: Airborne observations and modeling of springtime stratosphereto-troposphere transport over California, Atmos. Chem. Phys., 13, 12481-12494, doi:10.5194/acp-13-12481-2013, 2013.

Zanis, P., Gerasopoulos, E., Priller, A., Schnabel, C., Stohl, A., Zerefos, C., Gäggeler, H. W., Tobler, L., Kubik, P. W., Kanter, H. J., Scheel, H. E., Luterbacher, J., and Berger, M.: An estimate of the impact of stratosphere-to-troposphere transport 
(STT) on the lower free tropospheric ozone over the Alps using ${ }^{10} \mathrm{Be}$ and ${ }^{7} \mathrm{Be}$ measurements, J. Geophys. Res., 108, 8520, doi:10.1029/2002JD002604, 2003.
Zheng, X.-D., Shen, C.-D., Wan, G.-J., Liu, K.-X., Tang, J., and $\mathrm{Xu}, \mathrm{X} . \mathrm{B} .:{ }^{10} \mathrm{Be} /{ }^{7} \mathrm{Be}$ implies the contribution of stratospheretroposphere transport to the winter-spring surface $\mathrm{O}_{3}$ variation observed on the Tibetan Plateau, Chinese Sci. Bull., 56, 84-88, 2011. 